\title{
Radiation Enhanced Diffusion of Cesium, Strontium, and Europium in Silicon Carbide
}

\author{
S.S. Dwaraknath, G.S. Was \\ Department of Nuclear Engineering and Radiological Sciences, University of Michigan, 2355 Bonisteel \\ Blvd, Ann Arbor, MI 48109-2104, USA
}

\begin{abstract}
The radiation enhanced diffusion (RED) of three key fission products in SiC: cesium, europium, and strontium was investigated following ion irradiation at a damage rate of $4.6 \times 10^{-4}$ dpa $s^{-1}$ at temperatures between $900^{\circ} \mathrm{C}$ and $1,100^{\circ} \mathrm{C}$. The radiation enhancement of diffusion was as large as $10^{7}$ at $900^{\circ} \mathrm{C}$, and dropped to a value of 1 by $1,300^{\circ} \mathrm{C}$ for all but cesium grain boundary diffusion. Strontium and cesium exhibited several orders of magnitude enhancement for both mechanisms. Europium enhancement was greatest at $900^{\circ} \mathrm{C}$, but dropped to the thermal rates at $1,100^{\circ} \mathrm{C}$ for both mechanisms The trends in the RED mechanism correlated well with the point defect concentrations suggesting that both carbon and silicon vacancy concentrations are important for fission product diffusion. These constitute the first radiation-enhanced diffusion measurements of strontium, cesium and europium in $\mathrm{SiC}$.

Keywords: Diffusion, SIMS, Fission Product, SiC, TRISO, Radiation Enhanced

Diffusion, Cesium, Strontium, Europium
\end{abstract}

\section{Introduction}

Tristructural-isotropic (TRISO) coated fuel is the fuel form of choice for the Next Generation Nuclear Plant (NGNP) program that will demonstrate the technologies for fuel fabrication and qualification on an industrial scale. The fuel particles consist of kernels of uranium oxycarbide $(\mathrm{UCO})$ or uranium oxide $\left(\mathrm{UO}_{2}\right)$ that are then coated with a porous carbon buffer, a pyrolytic carbon layer (PyC), a $\mathrm{SiC}$ layer, and a final $\mathrm{PyC}$ Preprint submitted to Journal of Nuclear Materials 
15 layer, to produce a nominally $1 \mathrm{~mm}$ diameter particle. These fuel particles are able to survive extreme environments of $900^{\circ} \mathrm{C}-1,300^{\circ} \mathrm{C}$ under normal operating conditions and as high as $1,600^{\circ} \mathrm{C}$ in accident situations [1]. During operation, several fission products (FPs): silver, strontium and europium in particular, have been observed to be released through intact $\mathrm{SiC}[2]$. While significant research efforts have focused on quantifying

20 and identifying a mechanism for silver release through the $\mathrm{SiC}[3,4,5,6]$, little is known about other FPs such as europium and strontium. Cesium, europium, and strontium all pose important radiological health concerns if released to the environment [7]. Cesium diffusion has been assumed to be negligible as high quality fuel has shown minimal cesium release, but this has not been verified.

25 Post-irradiation annealing of fuel has shown several features in FP release curves that can not be interpreted without knowing the FP distribution in the fuel a priori. The low solubility of most FPs and low melting and boiling temperatures compared with the temperatures of interest makes diffusion couples very difficult to construct $[4,6]$. Several studies have attempted to isolate thermal and radiation enhanced diffusion (RED) for

30 FPs with little success. Ion implantation has been used to introduce FPs into SiC, but this is complicated by the introduction of trapping sites due to radiation damage from the implantation[8], and the likely change in diffusion mechanisms due to the very high concentrations necessary to measure the diffusion profiles $[3,5,9,10,11]$. One study investigated silver diffusion via ion implantation and SIMS at lower concentrations, but could not establish if those concentrations were above or below the solubility limit [12]. Spherical diffusion couples made using the same coaters for TRISO particle production have shown that grain boundaries play an important role in silver diffusion through SiC, but these experiments have been conducted at very high silver concentrations (pure silver at the interface) that are not relevant under fuel operating conditions [6]. The spherical 40 geometry also limits the analytical techniques for concentration profiling to those with poor sensitivity, significantly reducing the accuracy of the measured diffusion coefficients.

Recently a novel diffusion couple was developed that maintains a thin film geometry 
to allow the use of depth profiling techniques, introduces FPs into PyC adjacent to $\mathrm{SiC}$ without causing radiation damage in the $\mathrm{SiC}$ and at concentrations that would be relevant

45 to TRISO fuel, recreates the $\mathrm{PyC} / \mathrm{SiC}$ interface, and allows for the isolation of thermal diffusion [13]. This design was used to study the thermal diffusion of cesium, strontium, and europium between $900^{\circ} \mathrm{C}$ and $1,300^{\circ} \mathrm{C}$ reported in [14].This thin film geometry is well suited to conduct controlled RED experiments using ion irradiation to emulate neutron irradiation. This study investigated the role of radiation on fission product diffusion and

50 examines how this diffusion data fits with the fission product release measurements.

\section{Experimental Method}

\subsection{Materials}

Details of the novel diffusion couple design were reported in ref [13]. The diffusion couple is a substrate of high purity CVD $\beta$-SiC (grain size: $1.8 \mu \mathrm{m}$ ) obtained from Rohm and

55 Haas Inc., that was coated with $300 \mathrm{~nm}$ of PyC. The FP of interest: cesium, europium, or strontium was then implanted into the PyC. A final coating of plasma-enhanced CVD (PECVD) SiC sealed the diffusion couple to allow the FP to have sufficient residence time at the interface to diffuse into the $\mathrm{SiC}$ substrate. For this study, all three FPs were implanted at $400 \mathrm{keV}$ to a total fluence of $10^{16} \mathrm{~cm}^{-2}$. The energy was chosen to 60 ensure that the FP remained within the $\mathrm{PyC}$ and did not penetrate the $\mathrm{SiC}$ substrate, allowing for the calculation of purely thermal diffusion coefficients within the $\mathrm{SiC}$ and the controlled measurement of RED as performed in this study.

\subsection{Ion Irradiation}

High temperature irradiations were performed using a 3 MV Pelletron accelerator at the University of Michigan Ion Beam Laboratory. Figure 1 is a schematic of the irradiation chamber that was designed to allow for accurate dose and temperature monitoring. Temperature was monitored using both a thermocouple mounted on the sample surface and a 2D infrared pyrometer. Damage level was monitored using a Faraday cup inserted 


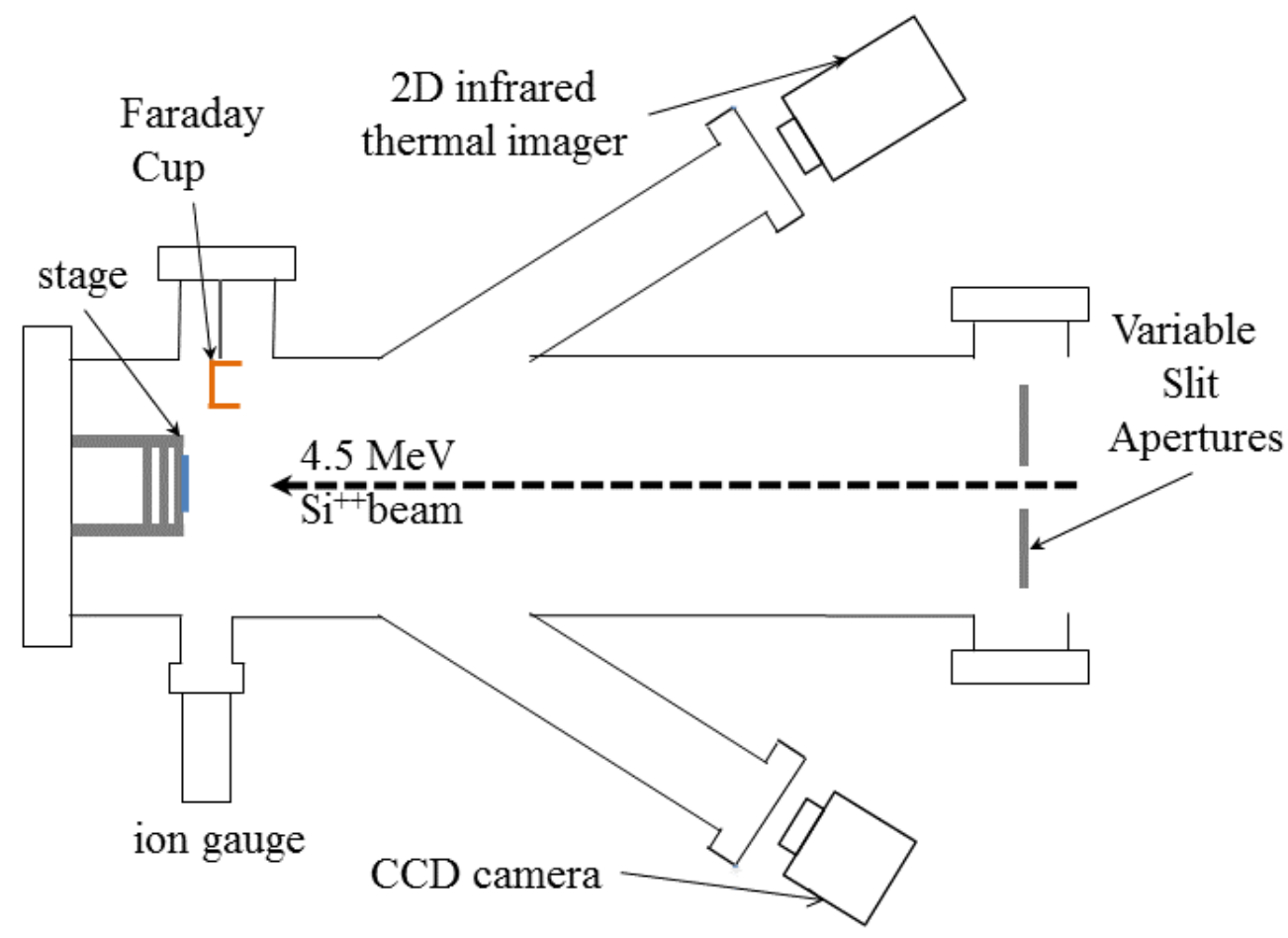

Figure 1: Schematic of the irradiation chamber. A $4.5 \mathrm{MeV} \mathrm{Si}{ }^{++}$beam is used to irradiate the sample. A Faraday cup that can be inserted directly in front of the sample is used to measure dose. A set of variable slit apertures is used to control the irradiation area. A thermocouple on the stage and the $2 \mathrm{D}$ infrared thermal imager are used to monitor temperature. A CCD camera allows for monitoring of the entire setup. An ion gauge placed close to the stage monitors vacuum in the chamber.

directly in front of the stage. A $4.5 \mathrm{MeV} \mathrm{Si} i^{++}$beam was raster scanned over a set

of tantalum slits that define the irradiation area at $1,019 \mathrm{~Hz}$ horizontally and $117 \mathrm{~Hz}$ vertically.

Dose-rate was calculated at the $\mathrm{PyC} / \mathrm{SiC}$ substrate interface in the $\mathrm{SiC}$ using the Stopping Range of Ions in Matter (SRIM) code in quick Kinchin-Pease mode [15, 16] with a silicon atom displacement energy of $35 \mathrm{eV}$ and a carbon atom displacement energy 75 of $20 \mathrm{eV}$ [17]. A resistive graphite heater on the stage provides the majority of the heating, but the addition of beam-heating was required to reach the peak-temperature of $1,100^{\circ} \mathrm{C}$. This bounded the damage rate to at minimum $4.6 \times 10^{-4} d p a s^{-1}$. Figure 2 shows the damage and implanted ion concentration as a function of depth. Between the 


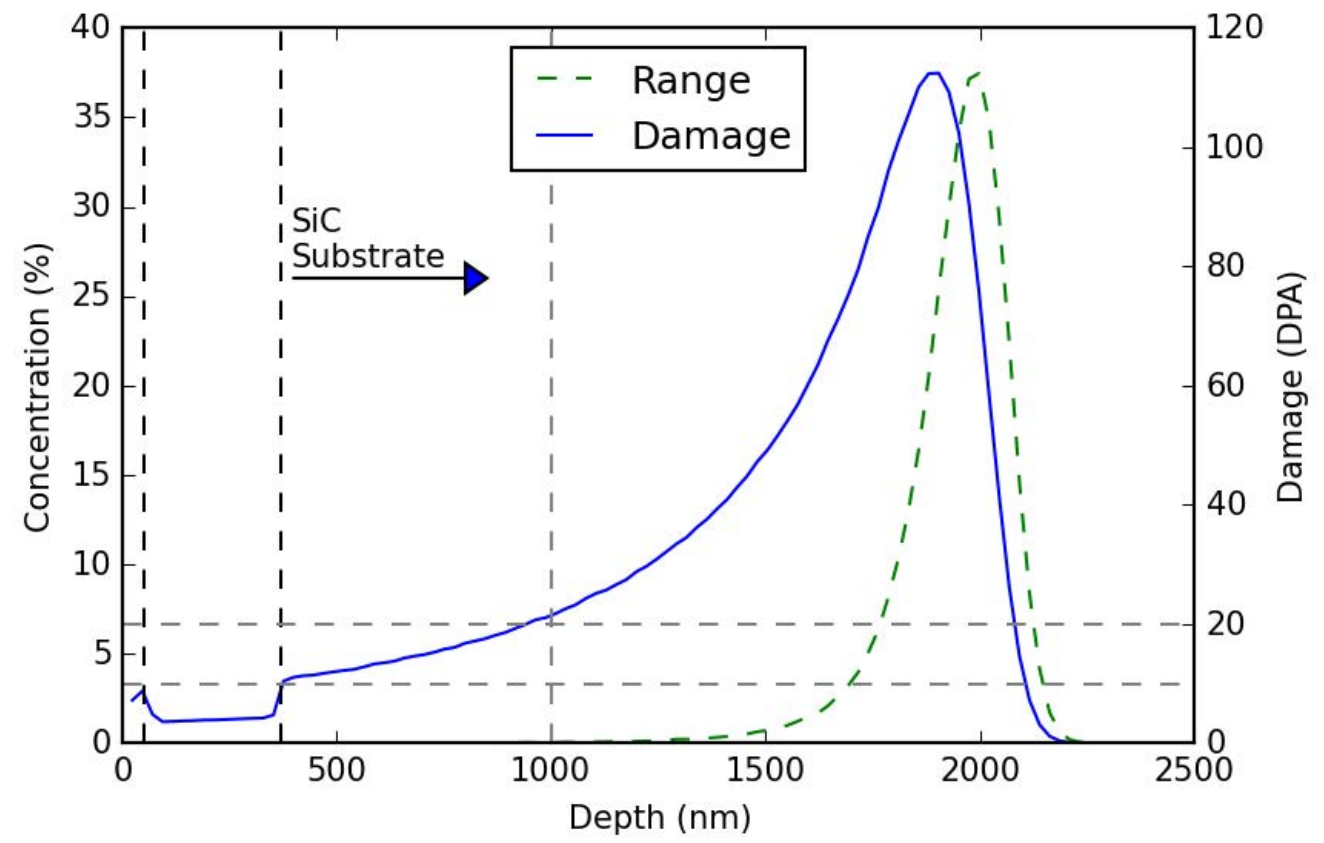

Figure 2: SRIM calculation of $4.5 \mathrm{MeV} \mathrm{Si}^{++}$into the diffusion couple. The layers are differentiated by vertical dashed black lines. horizontal grey lines mark the 10 and 20 dpa dose points which correspond to the PyC/SiC interface and $650 \mathrm{~nm}$ into the $\mathrm{SiC}$ substrate, within which all the RED is limited.

$\mathrm{PyC} / \mathrm{SiC}$ substrate interface at $350 \mathrm{~nm}$ and a depth of 1,000 $\mathrm{nm}$ the implanted silicon

concentration was minimal and the change in dose only varies by a factor of two. While this could affect the diffusion kinetics, the majority of the effect should be within the first $300 \mathrm{~nm}$ as witnessed in the thermal diffusion study, where the dose only varies by a factor of $50 \%$.

The sample temperature was monitored using a thermal imager and a thermocouple attached between the lip of a graphite shim and the diffusion couple surface. After initial heating, the 2D infrared pyrometer was calibrated to the surface emissivity using the thermocouple. The ion beam adds nearly $200^{\circ} \mathrm{C}$ of temperature increase due to beam heating as verified using the pyrometer. The thermocouple is protected from the beam and does not see this temperature increase. The surface temperature varied by $15^{\circ} \mathrm{C}$ 90 across the irradiated area. 


\subsection{Time of Flight Ion Mass Spectrometry}

Time of flight secondary ion mass spectrometry (ToF-SIMS) was used to profile the cesium, europium, and strontium concentrations for diffusion measurements using an IonTOF SIMS 5 at the Georgia Institute for Electronics Tech and Nanotechnology (IEN).

95 All ToF-SIMS spectra were acquired analyzing for positive ions using $25 \mathrm{keV} \mathrm{Bi}^{+}$to sputter material for analysis and $5 \mathrm{keV} \mathrm{O}^{+}$to sputter material for depth profiling. The sputtered craters were $100 \mu m \times 100 \mu m$ while only the center $50 \mu m \times 50 \mu m$ was analyzed to prevent edge effects that would reduce the depth resolution of the analysis. $\mathrm{SiC}$ substrates, ion implanted with cesium, strontium, or europium at $400 \mathrm{keV}$ to a fluence 100 of $10^{16} \mathrm{~cm}^{-2}$, were used as calibration standards for the depth profiles. Depth profiles of these standards with the same instrument parameters as the ion irradiated samples were use to calculate sputter rates and reduced sensitivity factors (RSF). The sputter rate was $1.16 \mathrm{~nm} / \mathrm{s}$. The RSFs were 5,400 ppm for cesium, 7,100 ppm for strontium, and $8,900 \mathrm{ppm}$ for europium.

\subsection{Diffusion Profiling and Calculation}

The Harrison model for grain boundary and bulk diffusion was used to classify the diffusion and an improved Whipple solution was used to calculate diffusion coefficients $[18,19]$. In the Harrison model there are three diffusion regimes: Type A which is bulk diffusion dominant, Type $\mathrm{C}$ which is grain boundary diffusion dominant and Type $\mathrm{B}$ which the mixed diffusion regime. A repeatable fitting model (criteria to evaluate the validity of the diffusion coefficient) and a thorough error propagation model have been developed and documented in ref [14]. A standard Fickian diffusion model was used to fit bulk diffusion profiles using:

$$
C_{B}(x)=C_{0}^{B} \exp \left(\frac{\left(x-x_{0}\right)^{2}}{4 D_{B} t}\right)
$$


The diffusion tails are presumed to be grain boundary diffusion as per ref [14], and were 115 fit using an exponential:

$$
C_{G B}(x)=C_{0}^{G B} \exp \left(-m * x^{6 / 5}\right)
$$

The triple product of the grain boundary diffusion coefficient $\left(D_{G B}\right)$, the segregation factor $(s)$, and the grain boundary width $(\delta)$ is then calculated from:

$$
s \delta D_{G B}=2 \sqrt{\frac{D_{B}}{t}}\left(0.77+\frac{\delta}{\sqrt{8 D_{B} t}}\right)^{5 / 3} m^{-5 / 3}
$$

A wide body of literature investigating diffusion in model systems has shown that the bulk vs. grain boundary diffusion model is credible $[20,21,22,23,24,25,26,27,28]$. SEM and TEM investigation of diffusion in TRISO have also identified grain boundary diffusion as a mechanism of diffusion for high yield FPs [29, 30, 31]. These profiles are directly fit to the error functions and exponentials to extract both diffusion coefficients and their errors from the fit. Grain boundary diffusion coefficients from Type B profiles have additional error from the bulk diffusion coefficient, which is factored in to their total error. The integrity of the SiC cap, the sensitivity of the SIMS instrument, the magnitude of the error compared with the diffusion coefficient and the ability to apply the Harrison model are all criteria used to validate diffusion profiles in this study.

\subsection{Point Defect Reaction Model}

The radiation enhancement of bulk diffusion is governed by the flux of point defects [32]. Radiation enhanced diffusion coefficients should follow the defect concentrations. At low irradiation temperatures the production of point defects overwhelms thermal defects and the concentrations grow to be so large that recombination of point defects dominates. As the temperature continues to rise the flux of point defects to sinks becomes significant, reducing the point defect concentrations. Eventually the thermally supported concentration of defects becomes significant and dominates the trend in defect 
concentrations.

The point defect reaction equations were solved for $\mathrm{SiC}$ to verify the temperature range in which the point defect concentrations transition from thermally dominated to radiation dominated and to determine whether these transitions are consistent with our results for cesium, europium and strontium RED. The vacancy and interstitial concentrations on the silicon and carbon sub-lattices are given by:

$$
\begin{aligned}
\frac{d C_{i}^{S i}}{d t}= & K_{0}^{S i}-k_{i i}^{S i} C_{i}^{S i} C_{i}^{S i}-k_{i v}^{S i} C_{i}^{S i} C_{v}^{S i} \\
& -k_{i i}^{S i C} C_{i}^{S i} C_{i}^{C}-k_{i v}^{S i-C} C_{i}^{S i} C_{v}^{C}-k_{i s}^{S i} C_{i}^{S i} C_{s} \\
\frac{d C_{v}^{S i}}{d t}= & K_{0}^{S i}-k_{i v}^{S i} C_{v}^{S i} C_{i}^{S i}-k_{v v}^{S i} C_{v}^{S i} C_{v}^{S i} \\
& -k_{i v}^{C-S i} C_{v}^{S i} C_{i}^{C}-k_{v v}^{S i C} C_{v}^{S i} C_{v}^{C}-k_{v s}^{S i} C_{i}^{S i} C_{s} \\
\frac{d C_{i}^{C}}{d t}= & K_{0}^{C}-k_{i i} C_{i}^{C} C_{i}^{S i}-k_{i v}^{C-S i} C_{i}^{C} C_{v}^{S i} \\
& -k_{i i}^{C} C_{i}^{C} C_{i}^{C}-k_{i v}^{C} C_{i}^{C} C_{v}^{C}-k_{i s}^{C} C_{i}^{S i} C_{s} \\
\frac{d C_{v}^{C}}{d t}= & K_{0}^{C}-k_{i v}^{S i-C} C_{i}^{S i} C_{v}^{C}-k_{v v}^{S i C} C_{v}^{S i} C_{v}^{C} \\
& -k_{i v}^{C} C_{i}^{C} C_{v}^{C}-k_{v v}^{C} C_{v}^{C} C_{v}^{C}-k_{v s}^{C} C_{i}^{C} C_{s}
\end{aligned}
$$

Here, $d C_{j}^{A} / d t$ is time differential for the concentration of species $j$ on sub-lattice $A$. $K_{0}^{S i}$ and $K_{0}^{C}$ are the damage production rates on either sub-lattice obtained from SRIM using the Kinchin-Pease mode to determine $K_{0}$ and the full cascade mode to calculate how the damage is partitioned to either sub-lattice [15]. $k_{j l}^{A}$ is the reaction rate coefficient between species $j$ and $l$ on sub-lattice $A$. 


\begin{tabular}{cc}
\hline \multicolumn{2}{c}{ Reaction Rate Coefficients $\left(\mathrm{cm}^{3} \mathrm{~s}^{-1}\right)$} \\
\hline$k_{i v}^{S i}$ & $4 \pi r_{i v}^{S i}\left(D_{i}^{S i}+D_{v}^{S i}\right)$ \\
$k_{i v}^{C}$ & $4 \pi r_{i v}^{C}\left(D_{i}^{C}+D_{v}^{C}\right)$ \\
$k_{i v}^{S i-C}$ & $4 \pi r_{i v}^{S i-C}\left(D_{i}^{S i}+D_{v}^{C}\right)$ \\
$k_{i v}^{C-S i}$ & $4 \pi r_{i v}^{C-S i}\left(D_{i}^{C}+D_{v}^{S i}\right)$ \\
$k_{i i}^{S i}$ & $4 \pi r_{i i}^{S i} 2 D_{i}^{S i}$ \\
$k_{i i}^{C}$ & $4 \pi r_{i i}^{C} 2 D_{i}^{C}$ \\
$k_{v v}^{S i}$ & $4 \pi r_{v v}^{S i} 2 D_{v}^{S i}$ \\
$k_{v v}^{C}$ & $4 \pi r_{v v}^{C} 2 D_{v}^{C}$ \\
$k_{i i}$ & $4 \pi r_{i i}\left(D_{i}^{S i}+D_{i}^{C}\right)$ \\
$k_{v v}$ & $4 \pi r_{v v}\left(D_{v}^{S i}+D_{v}^{C}\right)$ \\
$k_{i s}^{S i}$ & $4 \pi z_{i d} D_{i}^{S i}$ \\
$k_{v s}^{S S}$ & $4 \pi z_{v d} D_{v}^{S i}$ \\
$k_{i s}^{C}$ & $4 \pi z_{i d} D_{i}^{C}$ \\
$k_{v s}^{C}$ & $4 \pi z_{v d} D_{v}^{C}$ \\
\hline
\end{tabular}

Table 1: Reaction rate coefficients for the point defect reaction model.

There are two primary sinks in CVD-SiC: stacking faults and grain boundaries. Irradiation induced defects could also act as sinks, but their incorporation in the model is no different than stacking faults or grain boundaries which were evaluated to estimate the magnitude of effect of sinks on the point defect concentrations. Sinks strengths are given by $k_{m}^{2}$ where $m$ refers to particular sink. The sink strength for stacking faults is: $k_{s f}^{2}=z_{s f} C_{s f}$, where $z_{s f}$ is the bias to stacking faults and $C_{s f}$ is the stacking fault density. The bias for stacking faults is generally no more than $2 \%$ [32], and the stacking fault density in $\mathrm{SiC}$ is $10^{14} \mathrm{~cm}^{-2}$ [33], yielding a stacking fault sink strength of $1.02 \times 10^{14} \mathrm{~cm}^{-2}$. The sink strength for grain boundaries is: $k_{g b}^{2}=24 / d^{2}$, where $d$ is the grain size [32]. The grain size in the CVD SiC used in this study is $1.8 \mu m$ [13], yielding a grain boundary sink strength of $7.4 \times 10^{10} \mathrm{~cm}^{-2}$. The sink strength for stacking faults is three orders of magnitude higher than the sink strength for grain boundaries indicating that grain boundaries do not control the overall point defect concentrations reducing the sink term to annihilation at stacking faults.

Table 1 defines the reaction rate coefficients which are functions of the interaction radii and point defect diffusivities. The interstitial diffusivities are given in ref [34]. 


\begin{tabular}{cc}
\hline \multicolumn{2}{c}{ Diffusion Coefficients $\left(\mathrm{cm}^{2} \mathrm{~s}^{-1}\right)$} \\
\hline$D_{i}^{S i}$ & $1.23 \times 10^{-3} \exp \left(\frac{-0.74 \mathrm{eV}}{\mathrm{kT}}\right)$ \\
$D_{v}^{S i}$ & $8.36 \times 10^{7} \exp \left(\frac{-2.65 \mathrm{eV}}{\mathrm{k} T}\right)$ \\
$D_{i}^{C}$ & $3.3 \times 10^{-3} \exp \left(\frac{-1.53 \mathrm{eV}}{k T}\right)$ \\
$D_{v}^{C}$ & $2.62 \times 10^{8} \exp \left(\frac{-2.82 \mathrm{eV}}{k T}\right)$ \\
\hline
\end{tabular}

Table 2: Diffusion coefficients for the point defect reaction model.

\begin{tabular}{cc}
\hline Quantity & Value \\
\hline$a_{0}$ & $4.335 \AA[17]$ \\
$r_{i v}^{S i}$ & $48 / \sqrt{2} a_{0}=14.7 \mathrm{~nm}$ \\
$r_{i v}^{C}$ & $48 / \sqrt{2} a_{0}=14.7 \mathrm{~nm}$ \\
$r_{i v}^{S i-C}$ & $48 \sqrt{3} / 4 a_{0}=9.0 \mathrm{~nm}$ \\
$r_{i v}^{C-S i}$ & $48 \sqrt{3} / 4 a_{0}=9.0 \mathrm{~nm}$ \\
$r_{i i}^{S i}$ & $84 / \sqrt{2} a_{0}=25.7 \mathrm{~nm}$ \\
$r_{i i}^{C}$ & $84 / \sqrt{2} a_{0}=25.7 \mathrm{~nm}$ \\
$r_{v v}^{S i}$ & $84 / \sqrt{2} a_{0}=25.7 \mathrm{~nm}$ \\
$r_{v v}^{C}$ & $84 / \sqrt{2} a_{0}=25.7 \mathrm{~nm}$ \\
$r_{i i}^{S i C}$ & $84 \sqrt{3} / 4 a_{0}=15.8 \mathrm{~nm}$ \\
$r_{v v}^{S i C}$ & $84 \sqrt{3} / 4 a_{0}=15.8 \mathrm{~nm}$ \\
$z_{i d}$ & $1.02[32]$ \\
$z_{v d}$ & $0.98[32]$ \\
$C_{s}$ & $10^{14} \mathrm{~cm}-2[33]$ \\
$E_{m i}^{S i}$ & $0.74 \mathrm{eV}$ \\
$E_{m-v}^{S i}$ & $2.65 \mathrm{eV}$ \\
$E_{m}^{C}-i$ & $1.53 \mathrm{eV}$ \\
$E_{m-v}^{C}$ & $2.82 \mathrm{eV}$ \\
\hline
\end{tabular}

Table 3: Quantities for the point defect reaction model. 
Vacancy diffusivities were back-calculated from the self-diffusion coefficients [35] and the vacancy formation energies [36] assuming carbon and silicon self-diffusion in $\mathrm{SiC}$ occur by way of vacancies near the melting temperature $[37,38]$.

$$
\begin{gathered}
D^{S i}=D_{v}^{S i} C_{v}^{S i}+D_{i}^{S i} C_{i}^{S i} \approx D_{v}^{S i} C_{v}^{S i} \\
D^{C}=D_{v}^{C} C_{v}^{C}+D_{i}^{C} C_{i}^{C} \approx D_{v}^{C} C_{v}^{C} \\
D_{v}^{S i} \approx D^{S i} / C_{v}^{S i} \\
D_{v}^{C} \approx D^{C} / C_{v}^{C}
\end{gathered}
$$

Table 2 lists the parameters used to calculate the resulting point defect diffusivities. The radii for point defect interaction are based on the geometry of the two interpenetrating FCC lattices and the nearest neighbor distances. The zinc-blende system is an FCC lattice with a two atom basis: one on the origin and another of the opposing type on $1 / 4$ the body diagonal. The geometry factors for nearest neighbor interactions on the same sub-lattice and opposing sub lattices are the same. The nearest neighbor distance for defects on the same sub-lattice is then the nearest neighbor distance of the FCC lattice which is $1 / \sqrt{2} a_{0}$. The nearest neighbor distance for opposing lattices is the basis distance or the nearest atom distance which is $\sqrt{3} /{ }_{4} a_{0}$. Table 3 defines the interaction radii and the parameters necessary to the point defect concentrations.

At steady-state, all the differentials of concentration with time in Eqs (4-7) are set equal to 0 , which leaves a set of coupled equations that can be solved numerically as a function of temperature. A scientific computing and analysis package,SciPy [39], was used to solve these coupled non-linear equations to determine the point defect concentration under ion-irradiation and neutron irradiation damage rates. 


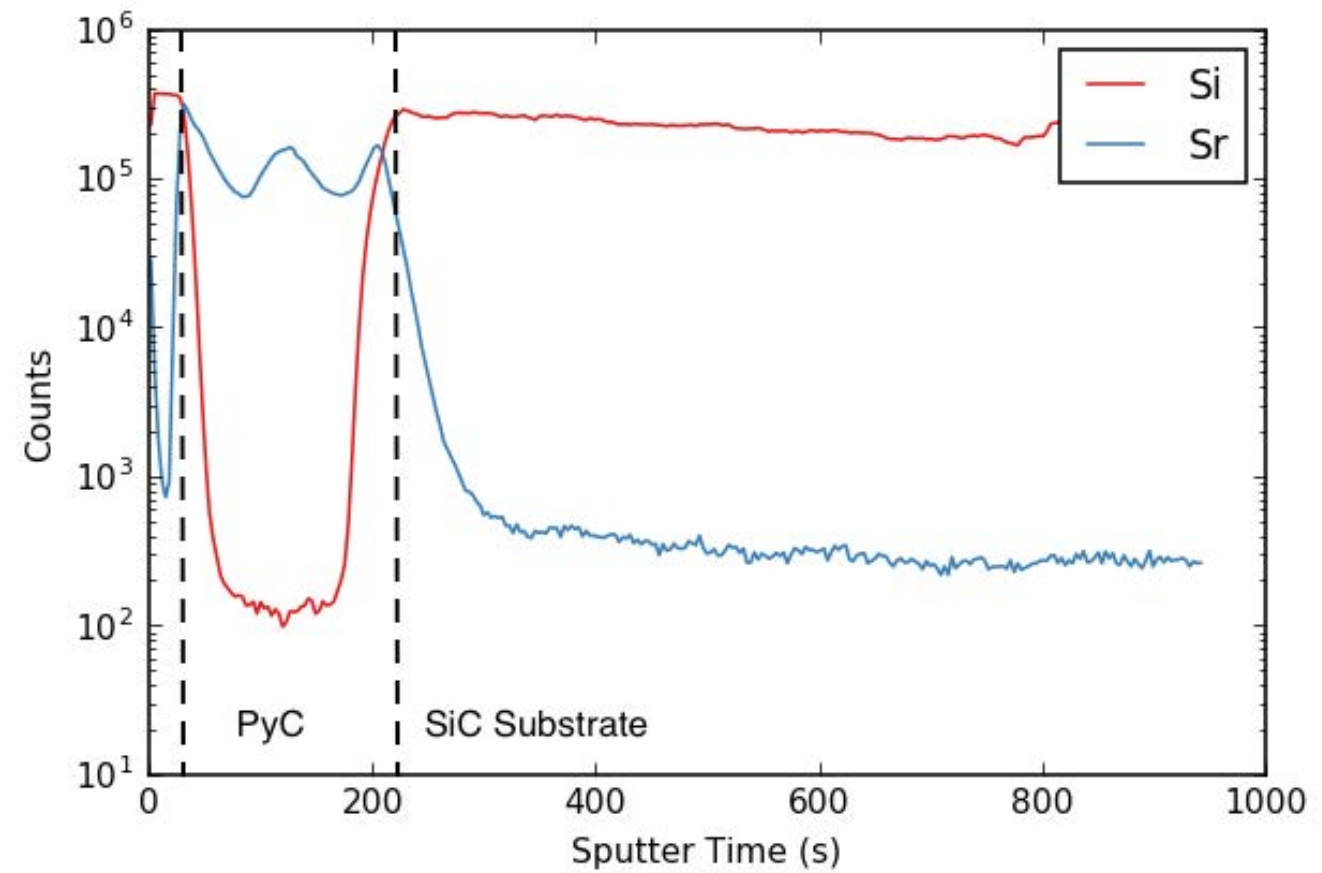

Figure 3: ToF-SIMS depth profile of the $900^{\circ} \mathrm{C} 6 \mathrm{hr} 10 \mathrm{dpa}$ strontium diffusion couple showing the silicon and strontium ion intensities. The $\mathrm{SiC}$ substrate and $\mathrm{PyC}$ layers are indicated with vertical dashed black lines. The layer before the PyC layer is the PECVD SiC cap.

\section{Results}

Figure 3 shows a ToF-SIMS ion intensity profile as a function of sputter time for strontium RED at $900^{\circ} \mathrm{C}$. The as-fabricated diffusion couple exhibited a $\mathrm{PyC} / \mathrm{SiC}$ interface full width at half maximum (FWHM) of $8 \mathrm{~nm}$ [14]. The irradiated condition exhibits an interface FWHM of $17 \mathrm{~nm}$, which is over double that of the initial FWHM. It also larger than the increase in FWHM from thermal annealing, which increased the interface width to $11 \mathrm{~nm}$ [14]. The FWHM is the primary source of error in the bulk diffusion coefficients. The SIMS profile indicates that strontium is enriching at the $\mathrm{PyC} / \mathrm{SiC}$ substrate interface, but does not provide enough information to indicate whether or not a chemical reaction is taking place that could alter the diffusion coefficient calculations.

Figure 4 shows the strontium concentration profile in the $\mathrm{SiC}$ substrate after 40 hours of annealing or 6 hours of ion irradiation to $10 \mathrm{dpa}$ at $900^{\circ} \mathrm{C}$. There is drastic increase 


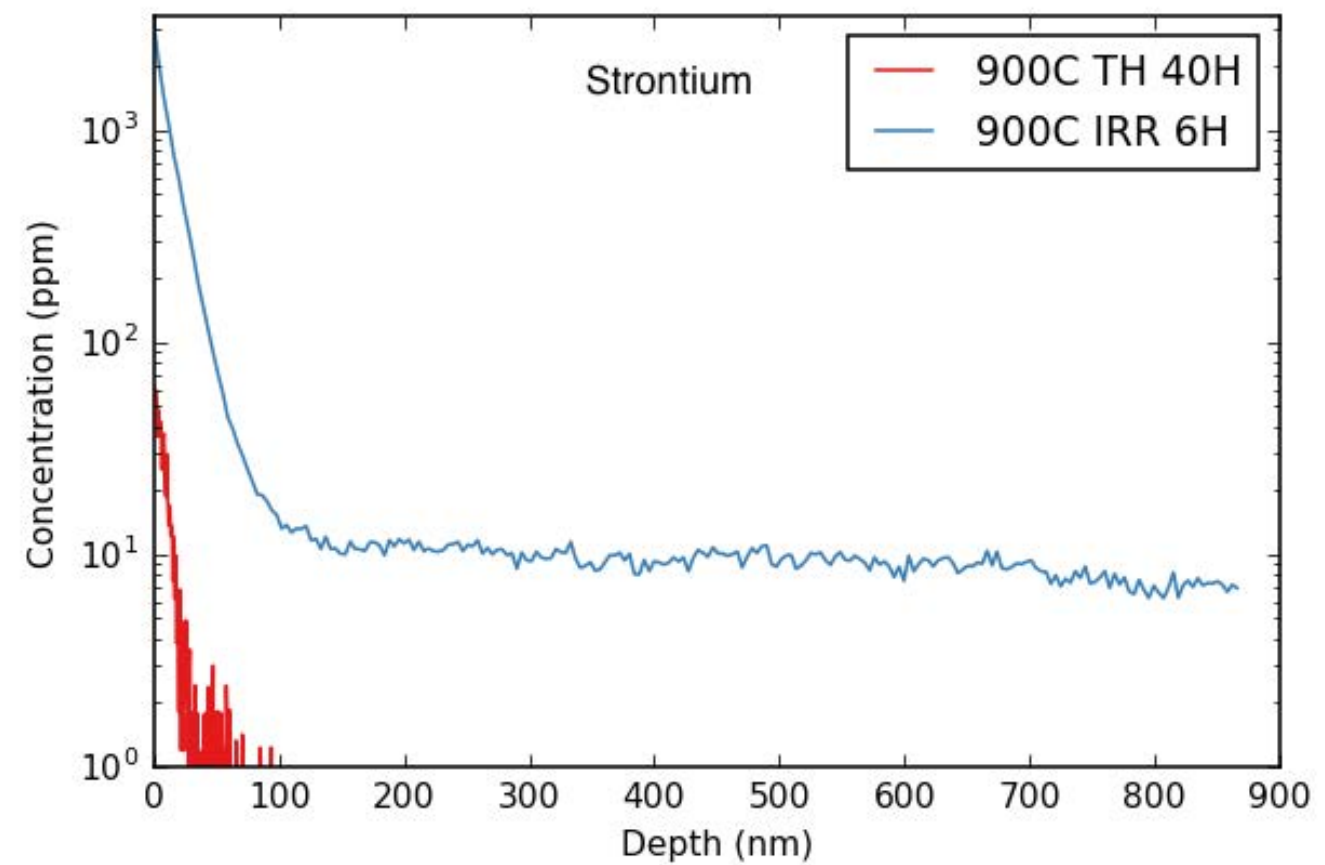

Figure 4: Comparison of the strontium concentration profiles in the $\mathrm{SiC}$ substrate for the thermally annealed and ion irradiated conditions at $900^{\circ} \mathrm{C}$. 


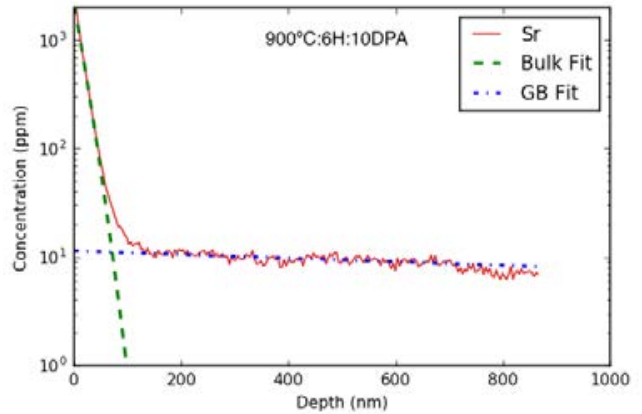

(a)

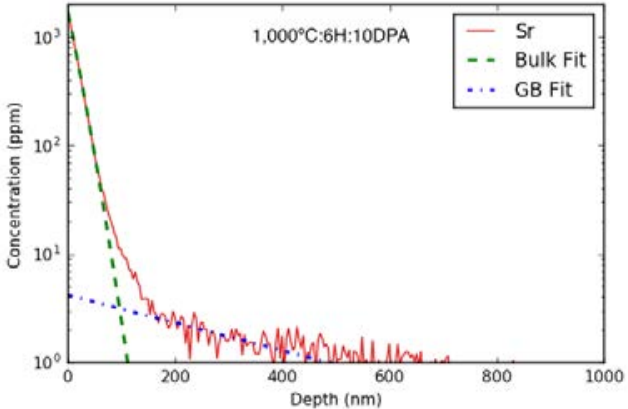

(b)

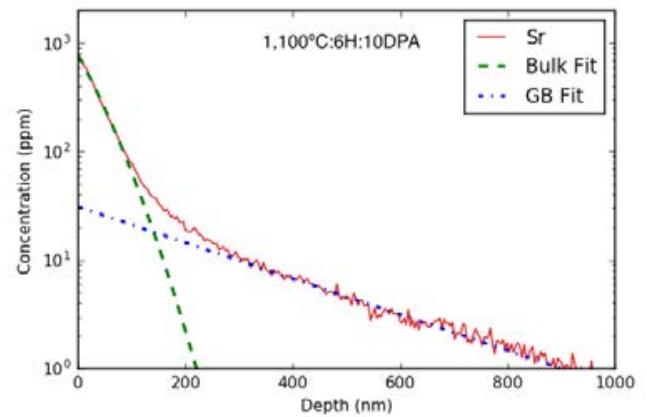

(c)

Figure 5: Strontium concentration profiles after ion irradiaiton at a dose rate of $4.6 \times 10^{-4} d p a s^{-1}$ to 10 dpa at (a) $900^{\circ} \mathrm{C}$ (b) $1,000^{\circ} \mathrm{C}$ and (c) $1,100^{\circ} \mathrm{C}$. 


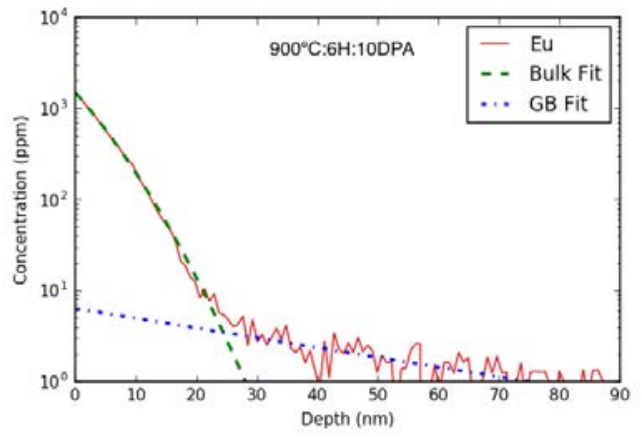

(a)

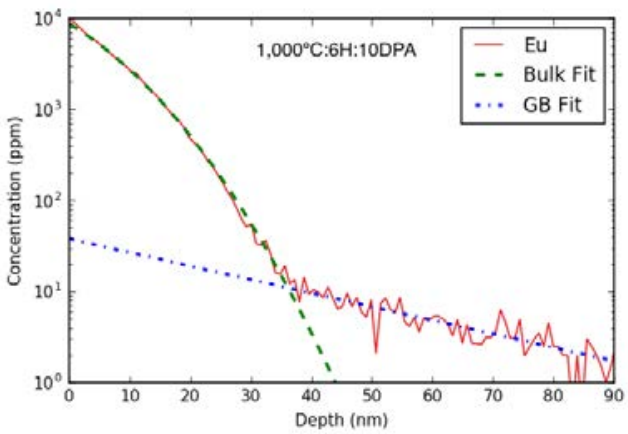

(b)

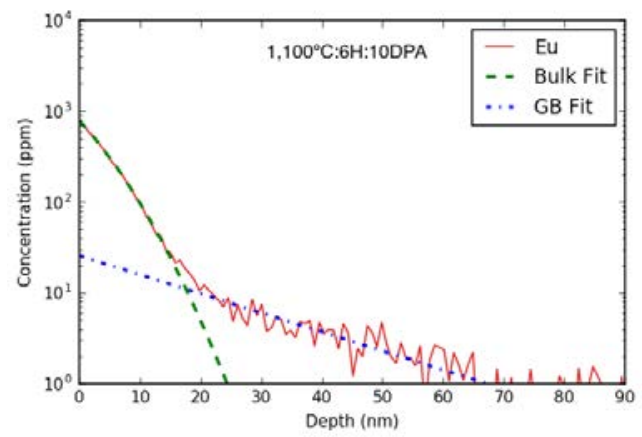

(c)

Figure 6: Europium concentration profiles after ion irradiaiton at a dose rate of $4.6 \times 10^{-4} d p a s^{-1}$ to 10 dpa at (a) $900^{\circ} \mathrm{C}$ (b) $1,000^{\circ} \mathrm{C}$ and (c) $1,100^{\circ} \mathrm{C}$. 


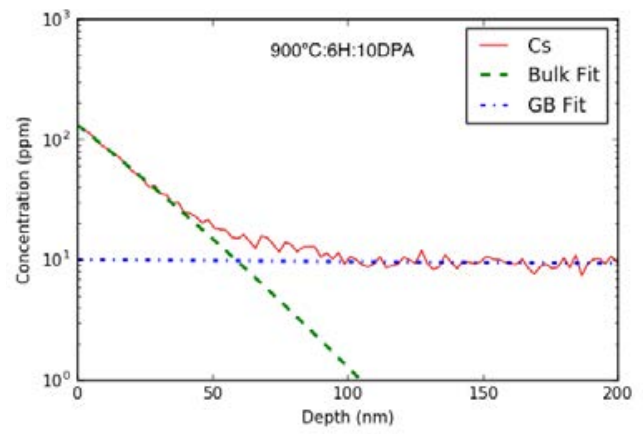

(a)

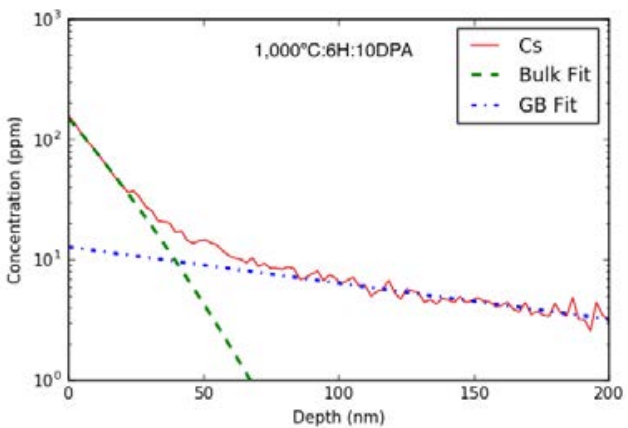

(b)

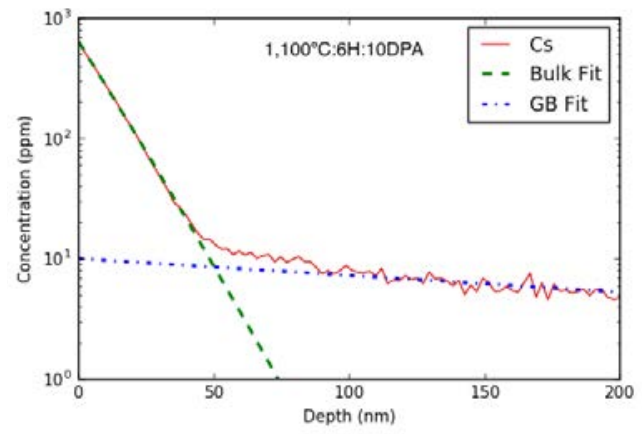

(c)

Figure 7: Cesium concentration profiles after ion irradiaiton at a dose rate of $4.6 \times 10^{-4} \mathrm{dpa} \mathrm{s}^{-1}$ to 10 dpa at (a) $900^{\circ} \mathrm{C}$ (b) $1,000^{\circ} \mathrm{C}$ and (c) $1,100^{\circ} \mathrm{C}$. 
in the penetration depth of the strontium between thermal annealing and irradiation.

The shape of the concentration also changes from a Fickian diffusion front indicative of grain boundary diffusion dominant kinetics under thermal annealing[14] to mixed diffusion kinetics where both bulk and grain boundary diffusion are significant under ion irradiation.

Figure 5 shows the concentration profiles for strontium diffusion under irradiation at $900^{\circ} \mathrm{C}, 1,000^{\circ} \mathrm{C}$ and $1,100^{\circ} \mathrm{C}$. Strontium exhibited mixed diffusion kinetics at all three temperatures. The Fickian diffusion fronts were fit with Eq. 1, while the grain boundary diffusion tails were fit with Eq. 2. The bulk penetration of strontium increases from $100 \mathrm{~nm}$ at $900^{\circ} \mathrm{C}$ to nearly $200 \mathrm{~nm}$ at $1,100^{\circ} \mathrm{C}$. The grain boundary tail is nearly flat at $900^{\circ} \mathrm{C}$, indicating very fast grain boundary diffusion kinetics to a much steeper slope with a grain boundary penetration depth of nearly $900 \mathrm{~nm}$.

Figure 6 shows the concentration profiles for europium diffusion under irradiation at $900^{\circ} \mathrm{C}, 1,00^{\circ} \mathrm{C}$, and $1,100^{\circ} \mathrm{C}$. Europium also exhibited mixed diffusion kinetics at all three temperatures. Europium diffusion exhibited much shallower penetration depths than strontium. The bulk penetration depth does not increase monotonically due to the large difference in interface concentrations for the $1,000^{\circ} \mathrm{C}$, and $1,100^{\circ} \mathrm{C}$. The diffusion coefficient is represented by the shape of the concentration profile, so this discrepancy in interface concentration should not affect the final diffusion coefficient calculation.

Figure 7 shows the concentration profiles for cesium diffusion under irradiation at $900^{\circ} \mathrm{C}, 1,00^{\circ} \mathrm{C}$, and $1,100^{\circ} \mathrm{C}$. Cesium also exhibited mixed diffusion kinetics at all three temperatures. The bulk diffusion front drops from $55 \mathrm{~nm}$ at $900^{\circ} \mathrm{C}$ to $40 \mathrm{~nm}$ at $1,100^{\circ} \mathrm{C}$. The grain boundary tail is nearly flat at $900^{\circ} \mathrm{C}$, drops to a penetration depth of nearly $400 \mathrm{~nm}$ at $1,000^{\circ} \mathrm{C}$ and then flattens out at $1,100^{\circ} \mathrm{C}$ indicating that there may be an inflection point around $1,000^{\circ} \mathrm{C}$ in the grain boundary diffusivity of cesium.

Table 4 lists the diffusion coefficients calculated in this study, as well as the relative errors. Figure 8 plots the RED coefficient as well as the thermal diffusion coefficients from ref [14]. Cesium and europium bulk diffusion exhibit a downward trend as temperature 


\begin{tabular}{cccccc}
\hline $\begin{array}{c}\text { Fission } \\
\text { Product }\end{array}$ & $\begin{array}{c}\text { Temperature } \\
{ }^{\circ} \mathrm{C}\end{array}$ & $\begin{array}{c}\text { Diffusion } \\
\text { Regime }\end{array}$ & $\begin{array}{c}D_{B} \\
\left(\mathrm{~cm}^{2} \mathrm{~s}^{-1}\right)\end{array}$ & $\begin{array}{c}s \delta D_{G B} \\
\left(\mathrm{~cm}^{3} \mathrm{~s}^{-1}\right)\end{array}$ & $\begin{array}{c}\text { Relative } \\
\text { Error } \\
(\%)\end{array}$ \\
\hline \multirow{3}{*}{ Cesium } & 900 & $\mathrm{~B}$ & $1.3 \pm 1.0 \times 10^{-15}$ & $1.7 \pm 1.1 \times 10^{-11}$ & 8 \\
& 1,000 & $\mathrm{~B}$ & $5.3 \pm 3.7 \times 10^{-16}$ & $6.3 \pm 4.5 \times 10^{-13}$ & 9 \\
& 1,100 & $\mathrm{~B}$ & $5.2 \pm 1.0 \times 10^{-16}$ & $1.1 \pm 0.2 \times 10^{-11}$ & 6 \\
Europium & 900 & $\mathrm{~B}$ & $3.4 \pm 1.8 \times 10^{-17}$ & $9.5 \pm 4.6 \times 10^{-15}$ & 3 \\
& 1,000 & $\mathrm{~B}$ & $3.3 \pm 1.6 \times 10^{-17}$ & $4.6 \pm 2.9 \times 10^{-15}$ & 6 \\
& 1,100 & $\mathrm{~B}$ & $2.2 \pm 1.1 \times 10^{-17}$ & $1.9 \pm 1.0 \times 10^{-15}$ & 7 \\
Strontium & 900 & $\mathrm{~B}$ & $7.0 \pm 4.3 \times 10^{-16}$ & $7.9 \pm 6.5 \times 10^{-11}$ & 3 \\
& 1,000 & $\mathrm{~B}$ & $1.2 \pm 0.2 \times 10^{-15}$ & $7.6 \pm 3.6 \times 10^{-12}$ & 9 \\
\hline
\end{tabular}

Table 4: Radiation enhanced diffusion coefficients for cesium, strontium, and europium at a dose rate of $4.6 \times 10^{-4} \mathrm{dpa} s^{-1}$. The relative error is defined as the portion of the total error from the fit in the grain boundary tail.

increases while strontium bulk diffusion increases with increasing temperature. Both strontium and europium grain boundary diffusion exhibit downward trends, while cesium grain boundary diffusion has an inflection around $1,000^{\circ} \mathrm{C}$. Both cesium and strontium RED exhibit significant enhancement over thermal diffusion. Europium also exhibits an enhancement of RED over thermal diffusion, but the enhancement is eliminated by $1,100^{\circ} \mathrm{C}$.

Between $900^{\circ} \mathrm{C}$ and $1,100^{\circ} \mathrm{C}$ all three elements exhibit Type B diffusion at all three temperatures. Since strontium was the only element observed to exhibit grain boundary diffusion dominant kinetics at $900^{\circ} \mathrm{C}$ under purely thermal conditions, it is also the only element to change diffusion regime in this study. Both cesium and europium exhibit a significant decrease in the interface concentration under irradiation vs thermal conditions, while strontium exhibits a significant increase at $900^{\circ} \mathrm{C}$ that is reduced in magnitude at $1,100^{\circ} \mathrm{C}$. The $900^{\circ} \mathrm{C}$ interfacial enrichment for strontium is likely due to the difference in diffusion regime from grain boundary diffusion dominant, where the interface concentration is the grain boundary concentration, to mixed diffusion dominant, where the interface concentration is the matrix concentration.

Table 5 lists the activation energies for RED. It was not possible to fit an Arrhenius 


\begin{tabular}{ccccc}
\hline $\begin{array}{c}\text { Fission } \\
\text { Product }\end{array}$ & $\begin{array}{c}D_{0}^{B} \\
\left(\mathrm{~cm}^{2} \mathrm{~s}^{-1}\right)\end{array}$ & $\begin{array}{c}E_{B} \\
(\mathrm{eV})\end{array}$ & $\begin{array}{c}s \delta D_{0}^{G B} \\
\left(\mathrm{~cm}^{3} \mathrm{~s}^{-1}\right)\end{array}$ & $\begin{array}{c}E_{G B} \\
(\mathrm{eV})\end{array}$ \\
\hline Cesium & $1.7 \pm 4.7 \times 10^{-17}$ & $-0.4 \pm 0.3$ & $\mathrm{ND}$ & $\mathrm{ND}$ \\
Europium & $1.9 \pm 2.9 \times 10^{-18}$ & $-0.3 \pm .2$ & $1.7 \pm 1.3 \times 10^{-19}$ & $-1.1 \pm 1.0$ \\
Strontium & $3.6 \pm 1.9 \times 10^{-9}$ & $1.6 \pm 0.6$ & $1.1 \pm 0.7 \times 10^{-16}$ & $-1.2 \pm 0.7$ \\
\hline
\end{tabular}

Table 5: Activation energies and pre-factors for bulk and grain boundary RED of cesium, europium, and strontium.

curve to the cesium grain boundary RED values. The activation energies for strontium and europium diffusion are very similar under purely thermal conditions[14]. Under irradiation, strontium RED is faster than either europium or cesium RED for either mechanism. Cesium and europium bulk diffusion both trend down as a function of temperature, while europium and strontium grain boundary diffusion trend down as a function of temperature. Cesium diffusion exhibits an inflection at $1,000^{\circ} \mathrm{C}$. Only strontium bulk RED exhibits the expected behavior of a thermally controlled process as a function of temperature.

\section{Discussion}

Figure 9 shows the radiation enhancement for bulk and grain boundary diffusion tion to that under thermal conditions. The enhancement in bulk diffusion is plotted in blue while the enhancement in grain boundary diffusion is plotted in red. At $900^{\circ} \mathrm{C}$ all three elements show significant enhancement of diffusion via the bulk and grain boundaries. This enhancement is negligible by $1,100^{\circ} \mathrm{C}$ for europium bulk and grain boundary diffusion. Strontium bulk and grain boundary radiation enhancement both become negligible by $1,300^{\circ} \mathrm{C}$. Cesium bulk enhancement also becomes negligible by $1,100^{\circ} \mathrm{C}$, but the enhancement of cesium grain boundary diffusion is significant up to $1,300^{\circ} \mathrm{C}$. The difference for the enhancement of europium diffusion between bulk and grain boundaries is within an order of magnitude. This is the error of the thermal and RED coefficients indicating that the two mechanisms exhibit the same enhancement within error. The 


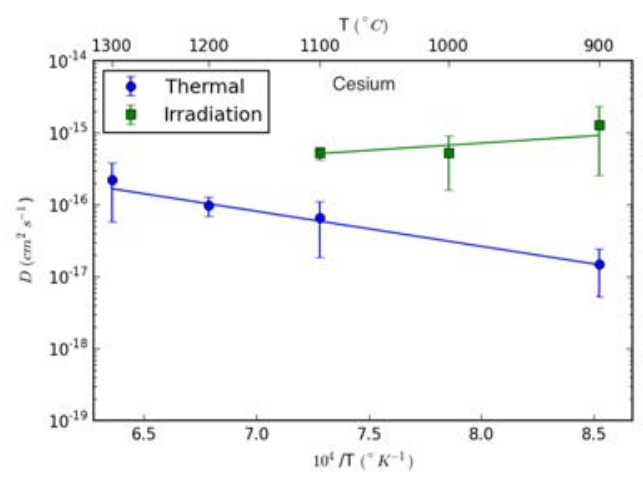

(a) cesium bulk diffusion

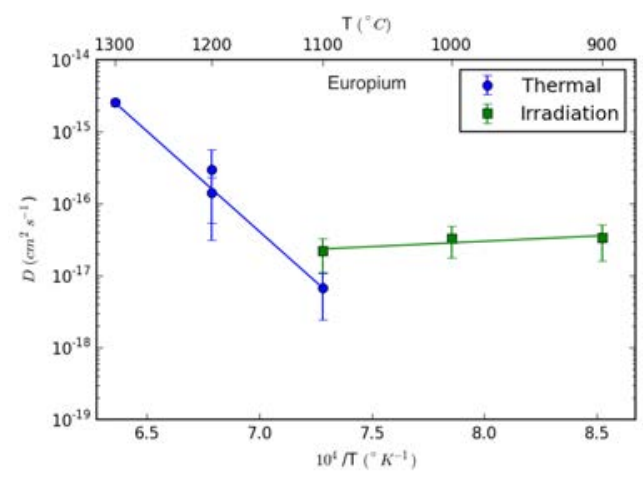

(c) europium bulk diffusion

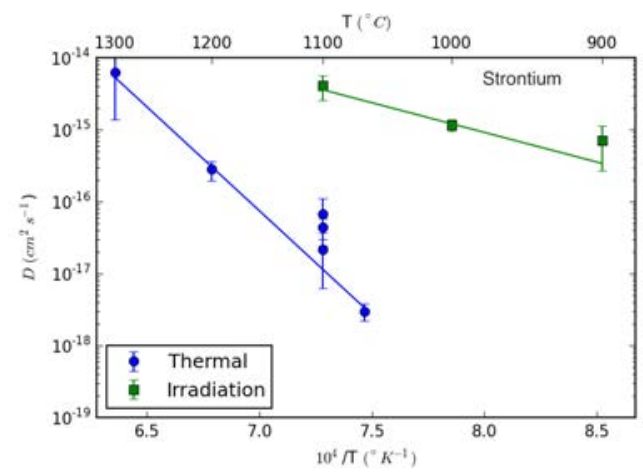

(e) strontium bulk diffusion

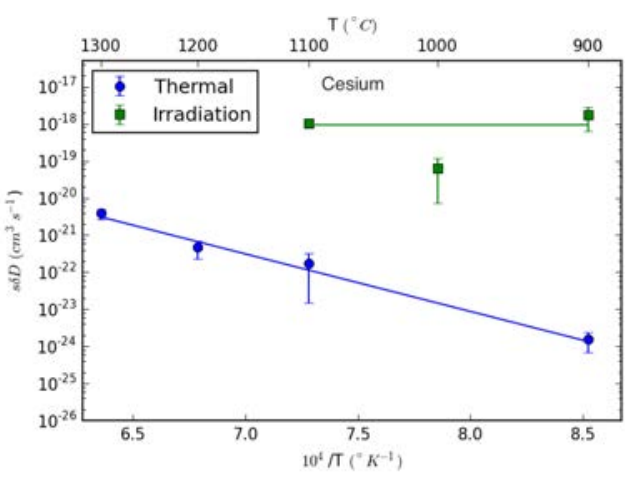

(b) cesium grain boundary diffusion

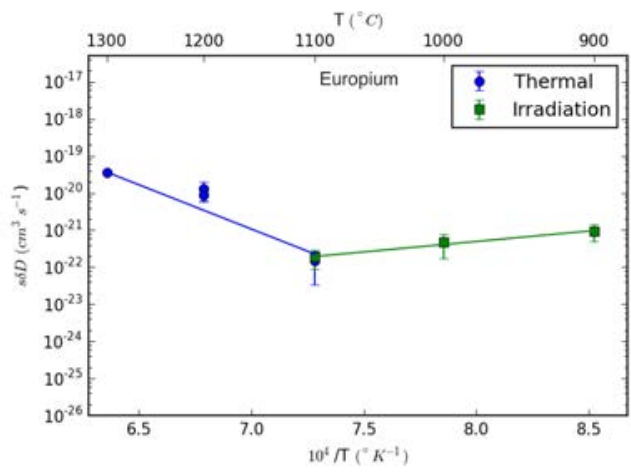

(d) europium grain boundary diffusion

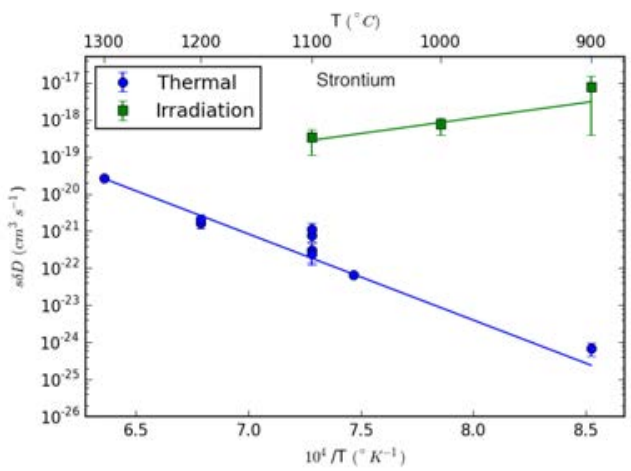

(f) strontium grain boundary diffusion

Figure 8: Thermal vs. RED for the bulk and grain boundary diffusion of cesium, europium, and strontium. Cesium grain boundary diffusion is assumed be athermal rather than inflecting at $1,000^{\circ} \mathrm{C}$. 


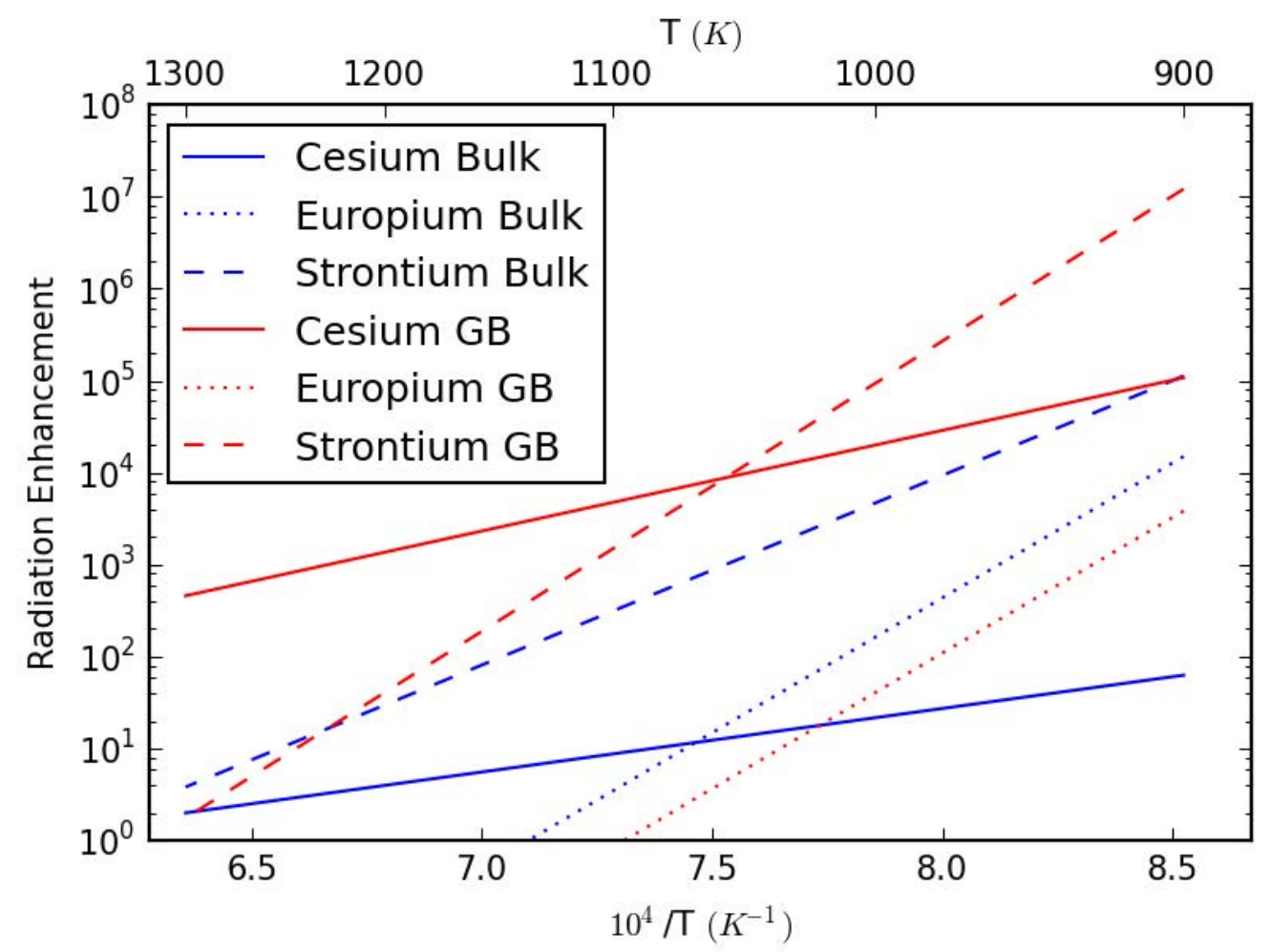

Figure 9: Radiation enhancement for fission product diffusion in $\mathrm{SiC}$ under the ion irradiation conditions. This study used $4.5 \mathrm{MeV} \mathrm{Si}{ }^{+}$ions at a dose rate of $4.6 \times 10^{-4} \mathrm{dpa} \mathrm{\textrm {s } ^ { - 1 }}$. Thermal diffusion was extrapolated down to $900^{\circ} \mathrm{C}$ when measured diffusion data was not available. 


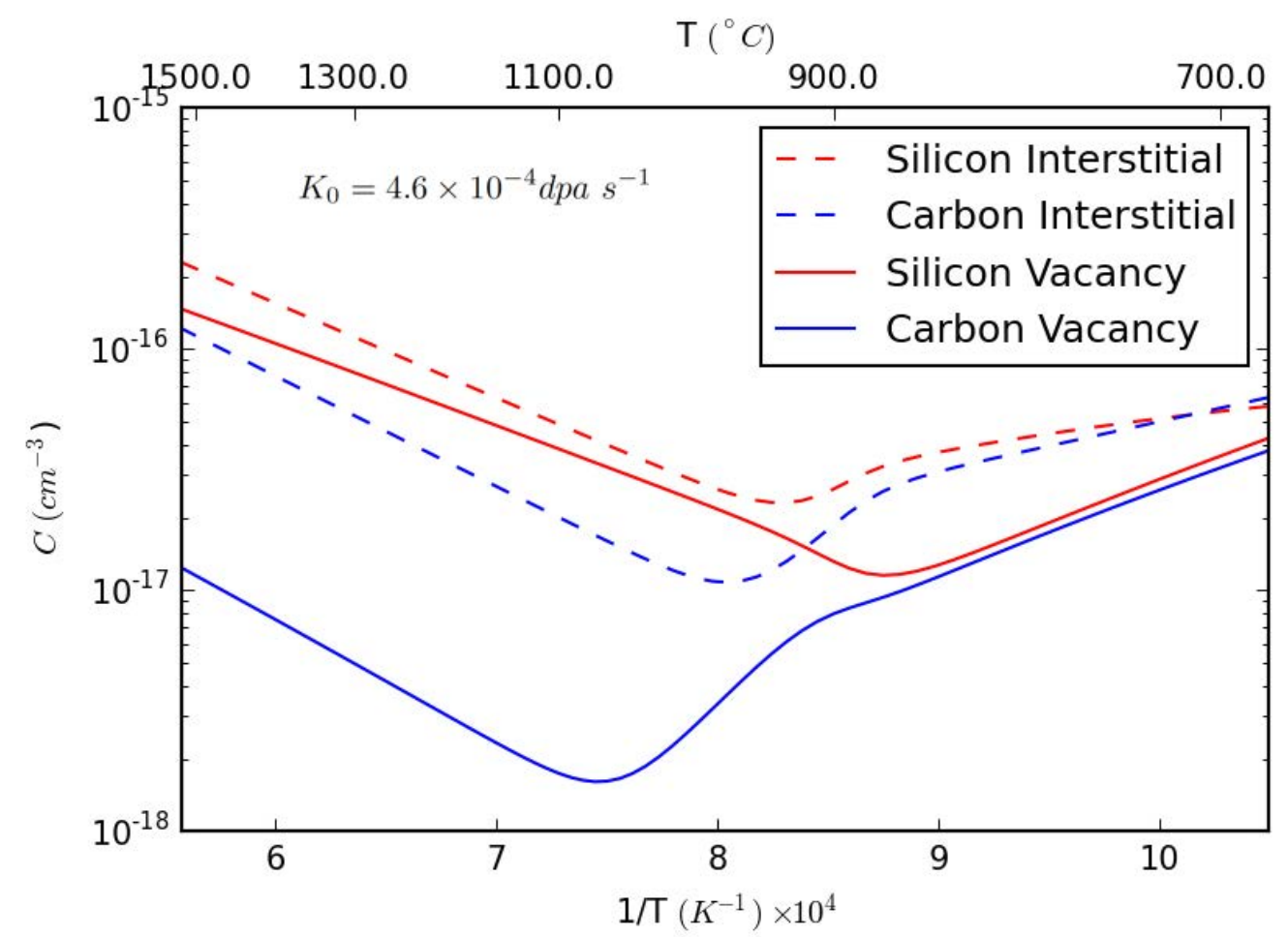

Figure 10: Point defect concentrations for SiC under ion-irradiation conditions. The solid lines are vacancy concentrations and the dashed lines are interstitial concentrations. The inflection points mark the thermal defect dominated regimes for the point defect concentration.

steeper slopes for the radiation enhancement of strontium and europium bulk diffusion vs. cesium bulk diffusion suggests that defect concentrations are more closely coupled with strontium and europium bulk diffusion than cesium bulk diffusion. The slope of the radiation enhancement for strontium and europium grain boundary diffusion is also steeper than the enhancement for cesium grain boundary diffusion. This could also imply that more defects are involved in the migration of strontium and europium than cesium for both bulk and grain boundary diffusion.

Figure 10 shows the point defect concentrations determined from Eqs. (4-7) under the ion irradiation conditions and using the parameters described in sections 2.2 and

2.5. The carbon vacancy concentration decreases with temperature between $900^{\circ} \mathrm{C}$ and $1,100^{\circ} \mathrm{C}$. Conversely, the silicon vacancy concentration monotonically increases between 


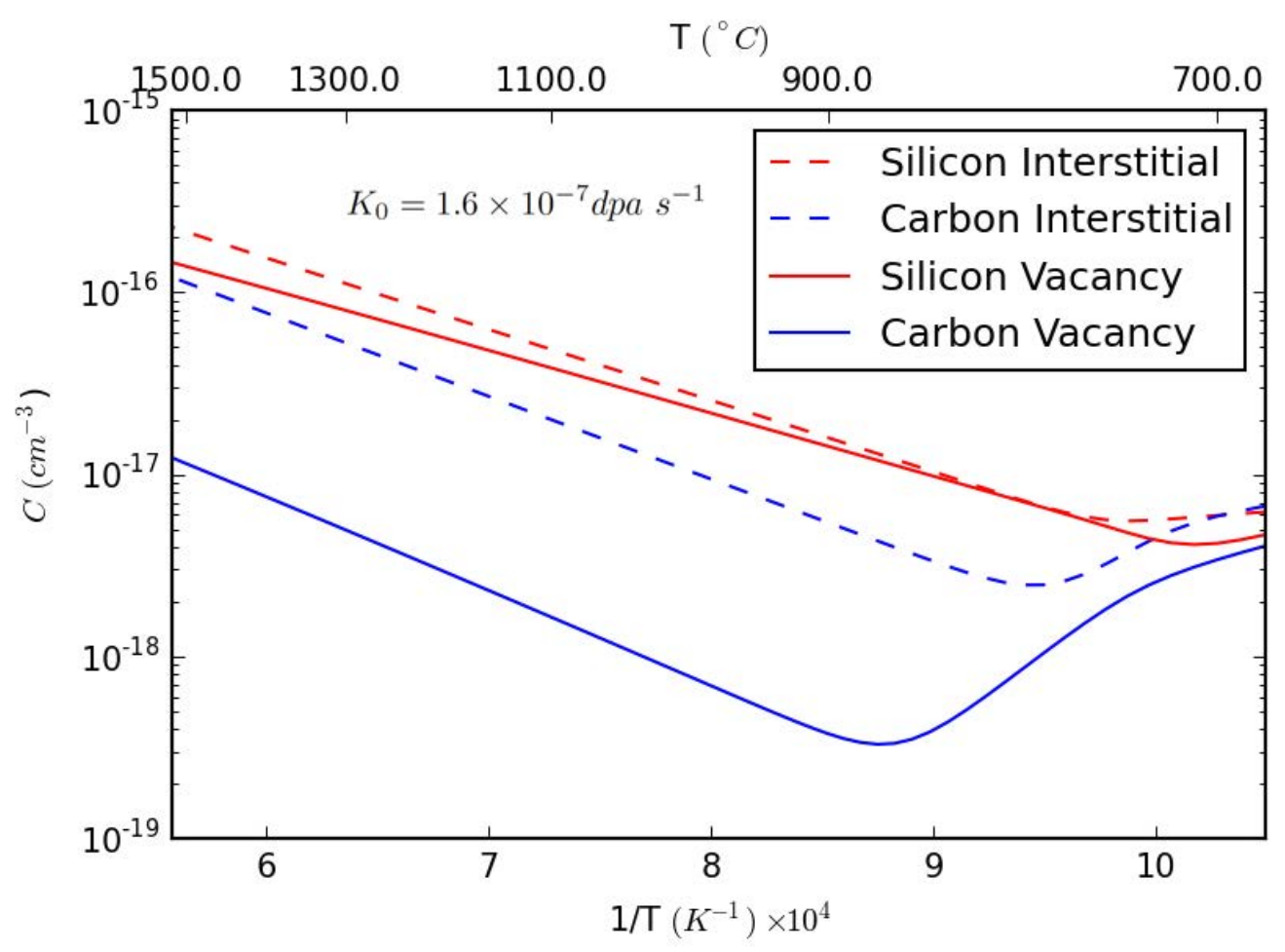

Figure 11: Point defect concentrations for SiC under neutron irradiation conditions. The solid lines are vacancy concentrations and the dashed lines are interstitial concentrations. The inflection points mark the thermal defect dominated regimes for the point defect concentration. 
$900^{\circ} \mathrm{C}$ and $1,100^{\circ} \mathrm{C}$. Both interstitial concentrations have inflection points, or "knees" in this temperature range. Figure 11 shows the point defect concentrations determined from Eqs. (4-7) using a dose rate of $1.6 \times 10^{-7} d p a s^{-1}$ which is relevant to neutron 275 irradiation conditions as per the AGR-1 fuel irradiation campaign conducted by INL at the Advanced Test Reactor [40]. The inflection points in the defect concentrations shift to much lower temperatures, below $900^{\circ} \mathrm{C}$, or the irradiation temperature range for AGR-1 and the expected operating temperature range for TRISO in a VHTR. This indicates that a neutron irradiation campaign would not be able to observe the inflection points in the diffusion coefficient to determine the sub-lattice and defects associated with FP diffusion in SiC. Similarly, they indicate that the RED of FPs in SiC under neutron irradiation will be monotonically increasing over the expected operating temperature range of a VHTR.

The thermal diffusion of all three FPs is strongly temperature dependent as shown in ref [14]. RED on the other hand is expected to be athermal or weakly thermal. The carbon vacancy concentration under ion irradiation decreases as a function of temperature up to $1,100^{\circ} \mathrm{C}$, in agreement with the weakly decreasing trends for cesium bulk, europium bulk, europium grain boundary and strontium grain boundary diffusion. Similarly, the weakly increasing trend for strontium bulk diffusion corresponds well with the positive temperature dependence of the silicon vacancy concentration. The inflection at $1,000^{\circ} \mathrm{C}$ for cesium grain boundary diffusion could correspond with either silicon or carbon interstitial concentration.

A sensitivity study was conducted to determine the effect of error in the parameters on the point defect concentrations. Defect migration energies in $\mathrm{SiC}$ are strong functions of the Fermi level which depend on the doping. The parameters used in this study assume that $\mathrm{SiC}$ is neither n-type or p-type, which could significantly alter the migration energies based on amount and type of fission products in $\mathrm{SiC}$. The migration energies have intrinsic errors on the order of $1 \mathrm{eV}[36,41,34]$. According to the model, the sensitivity of the point defect concentrations (significance), defined as the percent change in the point defect 
concentration per percent change in the parameter, to a single migration energy was 10.4 .

Concurrent changes in multiple migration energies resulted in larger significances and the significance to a change in all four migration energies was 2,700, indicating that there are strong coupling effects on the migration energies and the point defect concentrations. It is not possible to calculate diffusion coefficients directly from the point defect concentrations as the exact mechanism that defines how point defects mediate diffusion is not known. As a result, the absolute magnitude of the point defect concentrations and the relative magnitudes are of little consequence to the overall conclusions from this study, which focuses on the location of the inflection points to correlate fission product diffusion with a sub-lattice defect. The inflection points exhibited deviations of $100^{\circ} \mathrm{C}$ per $\mathrm{eV}$ change in the migration energies. The inflection points in the silicon interstitial and silicon vacancy concentrations are within $60^{\circ} \mathrm{C}$ of each other, which could change the defect on the silicon sub-lattice associated with strontium bulk diffusion. The sensitivity in the temperature of the inflection points does not affect the other conclusions.

At a dose rate relevant to ion irradiation, $4.6 \times 10^{-4} d p a s^{-1}$, the point defect concentrations are insensitive to any deviation in the sink density up to a sink density of $10^{18} \mathrm{~cm}^{-2}$, at which point the numerical solutions for the point defect concentrations became unstable. The insensitivity to sink density indicates that the defect concentrations are dominated by recombination. Irradiation induced defects such as loops, black dots and voids are unlikely to change this behavior, as they are not expected to increase the overall sink strength or sink density by four orders of magnitude. At a dose rate relevant to neutron irradiation conditions, $1.6 \times 10^{-7} d p a s^{-1}$, the point defect concentrations do change as a function of the sink density. The point defect concentrations exhibit a change of $0.08 \%$ per $\%$ change in the sink density. The inflections points exhibit deviations of $5.5 \times 10^{-4}{ }^{\circ} \mathrm{C}$ per $\%$ change in the sink density. This corresponds to a $0.55^{\circ} \mathrm{C}$ deviation the correlations between point defects and diffusivities identified in this study.

Figure 12 is an Arrhenius plot of cesium diffusion data from both the German and 


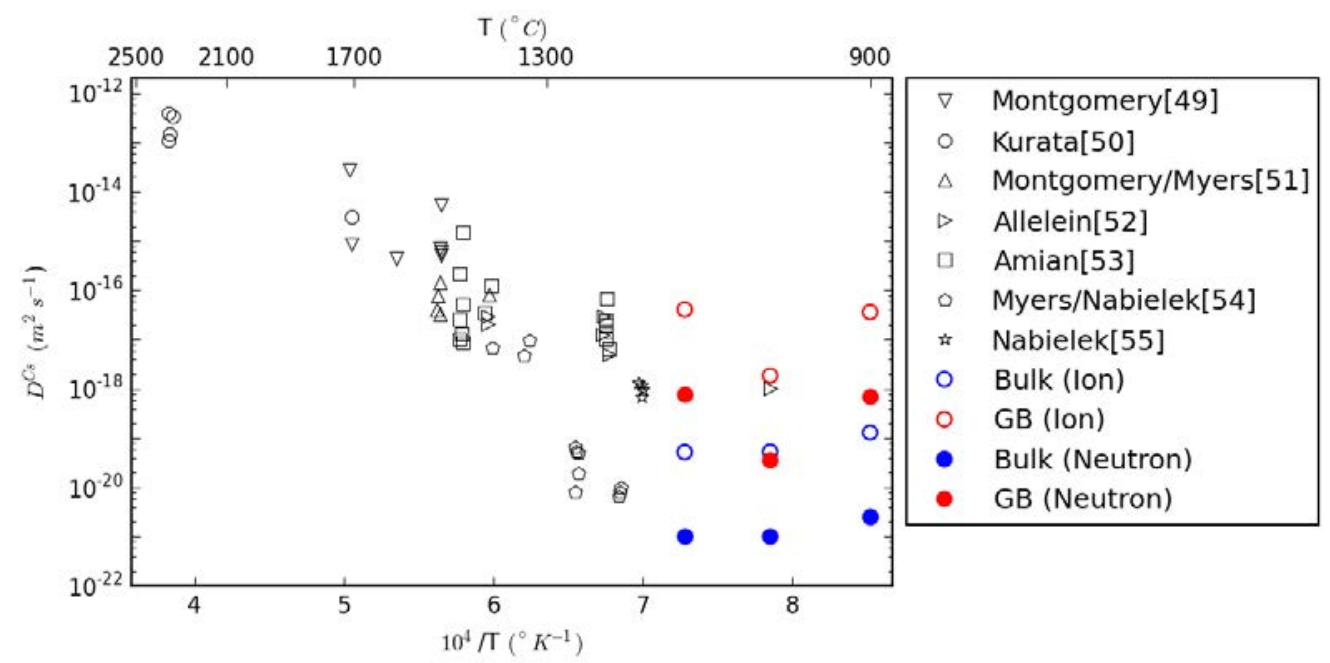

Figure 12: Arrhenius plot for cesium diffusion measured using post-irradiation heating experiments $[42,43,44,45,46,47,48,49]$. The ion irradiated bulk and grain boundary RED coefficients are plotted in red and blue open circles. Closed circles are for the dose rate corrected RED coefficients calculated by assuming that the diffusion coefficient scales by the square-root of the dose rate for a ion irradiation dose rate of $4.6 \times 10^{-4} d p a s^{-1}$ and a neutron dose rate of $1.7 \times 10^{-7} d p a s^{-1}$ [40].

the original US TRISO program used to calculate the fits for high temperature and low temperature diffusion mechanisms in the IAEA TECDOC-978. While they represent the best available data on diffusion in $\mathrm{SiC}$, these diffusion coefficients are an amalgamation of post-irradiation annealing of fuel spheres and compacts spanning three decades of test fuel. Different burn ups, fuel types, irradiation history, coating quality, and compact/fuel sphere matrix retention all affect the uncertainties on the plotted diffusion coefficients[2]. Further these diffusion coefficients have been calculated assuming that the $\mathrm{SiC}$ is the key retaining layer in preventing release to the environment, while several post-annealing examinations of fuel spheres and compacts have shown that the matrix graphite is an excellent retainer of cesium and strontium[50, 51, 52]. These complications introduce large uncertainties in the fitted diffusion coefficient that are not represented in the TECDOC. RED coefficients from the ion irradiations are plotted on top of the literature data for cesium in Figure 12. Bulk diffusion coefficients are plotted in blue while grain boundary diffusion coefficients are plotted in red using the segregation energy of $0.39 \mathrm{eV}$ and 0.5 
$\mathrm{nm}$ for the grain boundary width [14]. Open circles indicate diffusion coefficients from the ion irradiations. Under irradiation, the diffusion coefficients for cesium show a significant diffusion enhancement over those derived from TRISO fuel and straddle the low temperature fit from ref [2], suggesting that radiation damage could be a key component of the variability in cesium release.

To properly compare RED coefficients with the literature data, which are a result of reactor irradiations at much lower dose-rates, the RED coefficients have to be scaled to account for the difference in dose-rate. There are two limits on the scaling of the RED coefficients based on the microstructure that controls the point defect concentrations. One limit is when recombination of point defects controls the point defect concentrations, which occurs at low temperature and high dose-rates. The other limit is when annihilation of defects at sinks controls the point defect concentration, which occurs at high temperatures and low dose-rates. The definition of high and low temperature as well as high and low dose-rates are microstructure dependent [32]. As shown earlier, ion irradiations are closer to the recombination dominant regime and the neutron irradiations are closer to sink dominant regime. The exact scaling law is $D_{R E D} \propto K_{0}^{n}$, where $n$ is 0.5 for the recombination dominant regime and 1 for the sink dominant regime, and accounts for the likelihood that the two dose-rates are in different point defect regimes. The neutron dose rate corrected RED coefficients plotted in Figure 12 assume the scaling is $K_{0}^{0.5}$ to calculate the worst case diffusion coefficient for cesium release. These coefficients span the range between the thermal diffusion coefficients from ref [14] and the IAEA low temperature mechanism, suggesting that radiation is a key factor in the variability of cesium release.

There are two questions motivated by the diffusion data. The first is how a supersaturation of defects in the matrix could enhance grain boundary diffusion. The second is the origin of the difference between the RED coefficients and the thermal diffusion coefficients in the temperature range where the point defect concentrations should be thermally dominated. A more realistic model for grain boundaries can account for both 
of these.

The conventional model for grain boundaries treats them as a fast pathway of fixed concentration [53]. This works well if grain boundaries act as sinks with a well defined width at which point defects lose their identity [32]. In this case, defects can not mediate diffusion within the grain boundary and the grain boundary sink strength is unaffected by concentration changes within. In reality, both of these assumptions are likely to breakdown at the limit of a saturated grain boundary or highly over-sized solutes.

Recent density functional theory (DFT), molecular dynamics (MD), and kinetic Monte Carlo (kMC) simulations have shown that a point defect model for grain boundary diffusion produces the expected trends and migration barriers and can account for the variability in grain boundary diffusion coefficients as a function of structure $[54,55,56]$. In this model, point defect diffusion in the plane of the grain boundary mediates solute diffusion, which is the macroscopically measured grain boundary diffusion coefficient. A radiation induced super-saturation of point defects could then couple with the point defect concentration in the grain boundary and enhance diffusion.

Another model treats the grain boundary as a dynamic system similar to the lattice itself with distinct thermodynamic states [57]. The notion of a grain boundary complexion is then used to identify the various phases the grain boundary can exhibit depending on the environmental conditions such as temperature, pressure, and even local chemical potential and disorder. It is well understood that radiation can alter the phase stability of a material [32] and could alter the complexion stability of a grain boundary. In this paradigm, radiation doesnt just enhance diffusion via a microstructural coupling, but rather it alters the grain boundary itself and as a result, the diffusion coefficient. This complexion could be a higher diffusivity phase for some FPs but not others.

\section{Conclusion}

The radiation enhanced diffusion of cesium, europium, and strontium in CVD 3C-SiC was measured for the first time between $900^{\circ} \mathrm{C}$ and $1,100^{\circ} \mathrm{C}$ for bulk and grain boundary 
pathways. The enhancement in the diffusion coefficients due to irradiation is as large as $10^{7}$ at $900^{\circ} \mathrm{C}$, and due to a combination of a strong temperature dependence of thermal diffusion and a weak temperature dependence of RED for that element that drops to a value of 1 by $1,300^{\circ} \mathrm{C}$ for all but cesium grain boundary diffusion. A point defect model for bulk and grain boundary diffusion provides an explanation for the inflections in the diffusion coefficients of the various fission products. The decrease in cesium bulk, europium bulk, europium grain boundary, and strontium grain boundary RED with temperature correlates with the temperature dependence of the carbon vacancy concentration. Strontium bulk diffusion behavior follows the positive temperature dependence of the silicon vacancy concentration. The point defect model also indicates that these inflection points shift down in temperature under neutron irradiation conditions. Comparison with FP release from IAEA TECDOC-978 and AGR-1 suggest that RED is responsible for the variability in fission product release. The effect of RED on grain boundary diffusion may be explained by the 'complexion' or point defect model for grain boundaries.

\section{References}

[1] J. B. Malherbe, Diffusion of fission products and radiation damage in SiC, Journal of Physics D: Applied Physics 46 (47) (2013) 473001. doi:10.1088/0022-3727/46/47/473001.

URL http://stacks.iop.org/0022-3727/46/i=47/a=473001http://m.iopscience.iop.org/ 0022-3727/46/47/473001/article

[2] TECDOC - 978: Fuel Performance and Fission Product Behaviour in Gas-Cooled Reactors, Tech. rep., IAEA, Vienna (1997).

URL http://www-pub.iaea.org/books/IAEABooks/5633/Fuel-Performance-and-Fission-Product-Behaviour-in-Gas-Cooled

[3] H. Nabielek, P. E. Brown, P. Offermann, Silver release from coated particle fuel, Nuclear Technology 35 (2) (1977) 483-493.

URL http://www.scopus.com/inward/record.url?eid=2-s2.0-0017538421\&partnerID= tZOtx3y1http: //epubs. ans.org/?a=31908

[4] H. J. MacLean, Silver transport in CVD silicon carbide, Ph.D. thesis, Massachusetts Institute of Technology (2004).

URL http://dspace.mit.edu/handle/1721.1/17745 
[5] E. Friedland, J. Malherbe, N. van der Berg, T. Hlatshwayo, A. Botha, E. Wendler, W. Wesch, Study of silver diffusion in silicon carbide, Journal of Nuclear Materials 389 (2) (2009) 326-331. doi:10.1016/j.jnucmat.2009.02.022.

URL http://www.sciencedirect.com/science/article/pii/S0022311509003572

[10] E. Friedland, N. van der Berg, T. Hlatshwayo, R. Kuhudzai, J. Malherbe, E. Wendler, W. Wesch, Diffusion behavior of cesium in silicon carbide at $\mathrm{T}_{\dot{\iota}} 1000^{\circ} \mathrm{C}$, Nuclear Instruments and Methods in Physics Research Section B: Beam Interactions with Materials and Atoms 286 (286) (2012) 102-107. doi:10.1016/j.nimb.2011.11.048.

URL http://www.sciencedirect.com/science/article/pii/S0168583X11011505https://www. infona.pl//resource/bwmeta1 . element.elsevier-6d9fda1d-454c-3b71-8108-052065ab1af3

[11] E. Friedland, N. van der Berg, J. Malherbe, E. Wendler, W. Wesch, Influence of radiation damage on strontium and iodine diffusion in silicon carbide, Journal of Nuclear Materials 425 (1-3) (2012) 205-210. doi:10.1016/j.jnucmat.2011.10.032.

URL http://www.sciencedirect.com/science/article/pii/S0022311511009263

12] T. J. Gerczak, B. Leng, K. Sridharan, J. L. H. Jr., A. J. Giordani, T. R. Allen, Observations of 
ag diffusion in ion implanted sic, Journal of Nuclear Materials 461 (2015) 314 - 324. doi:http: //dx.doi.org/10.1016/j.jnucmat.2015.03.027.

URL http://www.sciencedirect.com/science/article/pii/S0022311515001749

[13] S. Dwaraknath, G. S. Was, Development of a multi-layer diffusion couple to study fission product transport in $\beta$-SiC, Journal of Nuclear Materials 444 (1-3) (2014) 170-174.

[14] S. Dwaraknath, G. Was, Thermal Diffusion of Cesium, Strontium, and Europium, Acta Materialia.

[15] J. F. Ziegler, M. Ziegler, J. Biersack, SRIM - The stopping and range of ions in matter (2010), Nuclear Instruments and Methods in Physics Research Section B: Beam Interactions with Materials and Atoms 268 (11-12) (2010) 1818-1823. doi:10.1016/j.nimb.2010.02.091. URL http://www.sciencedirect.com/science/article/pii/S0168583X10001862

[16] R. E. Stoller, M. B. Toloczko, G. S. Was, A. G. Certain, S. Dwaraknath, F. A. Garner, On the use of SRIM for computing radiation damage exposure, Nuclear Instruments and Methods in Physics Research, Section B: Beam Interactions with Materials and Atoms 310 (2013) 75-80. doi :10.1016/ j.nimb.2013.05.008. URL http://www.sciencedirect.com/science/article/pii/S0168583X13005053

[17] L. L. Snead, T. Nozawa, Y. Katoh, T.-S. Byun, S. Kondo, D. A. Petti, Handbook of SiC properties for fuel performance modeling, Journal of Nuclear Materials 371 (1-3) (2007) 329-377. doi:10. $1016 / j \cdot j n u c m a t .2007 .05 .016$.

URL http://www.sciencedirect.com/science/article/pii/S0022311507007623

[18] L. G. Harrison, Influence of dislocations on diffusion kinetics in solids with particular reference to the alkali halides, Transactions of the Faraday Society 57 (1961) 1191. doi:10.1039/tf9615701191. URL http://pubs.rsc.org/en/content/articlehtml/1961/tf/tf9615701191

[19] D. Gryaznov, J. Fleig, J. Maier, An improved procedure for determining grain boundary diffusion coefficients from averaged concentration profiles, Journal of Applied Physics 103 (6) (2008) 063717. doi: $10.1063 / 1.2887993$.

URL http://scitation.aip.org/content/aip/journal/jap/103/6/10.1063/1.2887993

[20] R. E. Hoffman, D. Turnbull, Lattice and Grain Boundary Self-Diffusion in Silver, Journal of Applied Physics 22 (5) (1951) 634. doi:10.1063/1.1700021.

URL http://scitation.aip.org/content/aip/journal/jap/22/5/10.1063/1.1700021

[21] J. Robinson, N. Peterson, Correlation effects in grain boundary diffusion, Surface Science 31 (1972) 586-616. doi : 10.1016/0039-6028(72)90276-2.

URL http://www.sciencedirect.com/science/article/pii/0039602872902762

[22] J. Sommer, C. Herzig, Direct determination of grain-boundary and dislocation self-diffusion coefficients in silver from experiments in type-C kinetics, Journal of Applied Physics 72 (7) (1954) 2758. doi $: 10.1063 / 1.352328$ 
URL http://scitation.aip.org/content/aip/journal/jap/72/7/10.1063/1.352328

[23] J. Bernardini, P. Gas, E. D. Hondros, M. P. Seah, The Role of Solute Segregation in Grain Boundary Diffusion, Proceedings of the Royal Society A: Mathematical, Physical and Engineering Sciences 379 (1776) (1982) 159-178. doi:10.1098/rspa.1982.0011. URL http://rspa.royalsocietypublishing.org/content/379/1776/159

[24] J. R. Farver, R. A. Yund, Measurement of oxygen grain boundary diffusion in natural, fine-grained, quartz aggregates, Geochimica et Cosmochimica Acta 55 (6) (1991) 1597-1607. doi:10.1016/ 0016-7037 (91) 90131-N.

URL http://www.sciencedirect.com/science/article/pii/001670379190131N

[25] A. C. S. Sabioni, A. M. Huntz, F. Millot, C. Monty, Self-diffusion in cr 2 o 3 III. Chromium and oxygen grain-boundary diffusion in polycrystals, Philosophical Magazine A 66 (3) (1992) 361-374. doi : 10.1080/01418619208201562.

URL http://www. tandf online.com/doi/abs/10.1080/01418619208201562\#. VY8WbvlVhBc

[26] J. Askill, G. B. Gibbs, Tracer Diffusion in $\beta$-Titanium, physica status solidi (b) 11 (2) (1965) 557565. doi:10.1002/pssb.19650110207.

URL http://doi.wiley.com/10.1002/pssb.19650110207

[27] K. Maier, H. Mehrer, E. Lessmann, W. Schüle, Self-diffusion in nickel at low temperatures, physica status solidi (b) 78 (2) (1976) 689-698. doi:10.1002/pssb.2220780230.

URL http://doi.wiley.com/10.1002/pssb. 2220780230

[28] J. Mimkes, M. Wuttig, Exact Solution for a Model of Dislocation Pipe Diffusion, Physical Review B 2 (6) (1970) 1619-1623. doi:10.1103/PhysRevB.2.1619.

URL http://link.aps.org/doi/10.1103/PhysRevB.2.1619

[29] I. van Rooyen, D. Janney, B. Miller, P. Demkowicz, J. Riesterer, Electron microscopic evaluation and fission product identification of irradiated TRISO coated particles from the AGR-1 experiment: A preliminary review, Nuclear Engineering and Design 271 (2014) 114-122. doi: 10.1016/j. nucengdes. 2013.11.019.

URL http://www.sciencedirect.com/science/article/pii/S0029549313006031

[30] I. van Rooyen, T. Lillo, Y. Wu, Identification of silver and palladium in irradiated TRISO coated particles of the AGR-1 experiment, Journal of Nuclear Materials 446 (1-3) (2014) 178-186. doi: 10.1016/j.jnucmat.2013.11.028.

URL http://www.sciencedirect.com/science/article/pii/S0022311513012658

[31] I. J. van Rooyen, E. Olivier, J. H. Neethlin, I. J. van Rooyen, E. Olivier, J. H. Neethlin, Investigation of the Distribution of Fission Products Silver, Palladium and Cadmium in Neutron Irradiated SIC using a Cs Corrected HRTEM. URL http://www.osti.gov/scitech/biblio/1166034 
[32] G. S. Was, Fundamentals of Radiation Materials Science: Metals and Alloys, Springer Science \& Business Media, 2007.

URL https://books.google. com/books?id=0N06swAJIOAC\&pgis=1

[33] L. Tan, T. Allen, J. Hunn, J. Miller, EBSD for microstructure and property characterization of the SiC-coating in TRISO fuel particles, Journal of Nuclear Materials 372 (2-3) (2008) 400-404. doi:10.1016/j.jnucmat.2007.04.048.

URL http://www.sciencedirect.com/science/article/pii/S0022311507007258

[34] F. Gao, W. Weber, M. Posselt, V. Belko, Atomistic study of intrinsic defect migration in 3C-SiC, Physical Review B 69 (24). doi:10.1103/PhysRevB.69.245205.

[35] D. P. Birnie, A Model for Silicon Self-Diffusion in Silicon Carbide: Anti-Site Defect Motion, Journal of the American Ceramic Society 69 (2) (1986) C-33-C-35. doi:10.1111/j.1151-2916.1986. tb04731.x.

URL http://doi.wiley.com/10.1111/j.1151-2916.1986.tb04731.x

[36] C. Wang, J. Bernholc, R. F. Davis, Formation energies, abundances, and the electronic structure of native defects in cubic SiC, Physical Review B 38 (17) (1988) 12752-12755. doi:10.1103/PhysRevB. 38.12752 .

URL http://link.aps.org/doi/10.1103/PhysRevB.38.12752

[37] M. H. Hon, R. F. Davis, Self-diffusion of $14 \mathrm{C}$ in polycrystalline $\beta$-SiC, Journal of Materials Science 14 (10) (1979) 2411-2421. doi:10.1007/BF00737031. URL http://link.springer.com/10.1007/BF00737031

[38] M. H. Hon, R. F. Davis, D. E. Newbury, Self-diffusion of 30Si in polycrystalline ?-SiC, Journal of Materials Science 15 (8) (1980) 2073-2080. doi:10.1007/BF00550634.

URL http://link.springer.com/10.1007/BF00550634

[39] E. Jones, T. Oliphant, P. Peterson, Others, \{SciPy\}: Open source scientific tools for $\{$ Python $\}$. URL http://www.scipy.org/

[40] R. Morris, C. Baldwin, F. Montgomery, T. Gerczak, C. Silva, J. Hunn, Performance of AGR-1 Fuel at Elevated Temperature: Fission Product Retention at 1600,1700, and 1800C, in: VHTR R\&D, Idaho Falls, ID, 2013.

[41] T. Oda, Y. Zhang, W. J. Weber, Study of intrinsic defects in 3C-SiC using first-principles calculation with a hybrid functional., The Journal of chemical physics 139 (12) (2013) 124707. doi:10.1063/ 1.4821937 .

URL http://scitation.aip.org/content/aip/journal/jcp/139/12/10.1063/1.4821937

[42] R. Martin, Compilation of Fuel Performance and Fission Product Transport Models and Database for MHTGR Design, Tech. Rep. ORNL/NPR-91/6, Oak Ridge National Laboratory (ORNL), Oak Ridge, TN (Oct. 1993). doi:10.2172/10199713. 
URL http://www.osti.gov/scitech/biblio/10199713

[43] F. Montgomery, Fission-product sic reaction in htgr fuel, Tech. rep., General Atomic Co., San Diego, CA (USA) (1981).

[44] Y. Kurata, K. Ikawa, K. Iwamoto, Fission product release from triso-coated uo 2 particles at 1940 to 2320 c, Journal of Nuclear Materials 98 (1) (1981) 107-115.

[45] F. MONTGOMERY, B. MYERS, N. PACKAN, Hrb-22 capsule irradiation test for htgr fuel (jaeri/usdoe collaborative irradiation test), JAERI-Research 98 (1998) 021.

[46] H. ALLELEIN, Fission product behavior in particular 137csin htr-triso-coated particle fuel, Jiil1695, Kernforschungsanlage Julich (Dec. 1980)(in German).

[47] W. Amian, D. Stöver, Diffusion of silver and cesium in silicon-carbide coatings of fuel particles for high-temperature gas-cooled reactors, Nuclear Technology 61 (3) (1983) 475-486.

[48] H. Nabielek, B. Myers, Fission product retention in htr fuel, in: Gas-cooled reactors today (Vol. 2). Advances in fuel, core and structural materials, 1982.

[49] R. Gontard, H. Nabielek, Performance evaluation of modern htr triso fuels, Forschungszentrum Jülich GmbH, HTA-IB-05/90.

[50] K. Fukuda, K. Iwamoto, Concentration profiles of fission products in the coating layers of irradiated fuel particles, Journal of Nuclear Materials 66 (1-2) (1977) 55-64. doi:10.1016/0022-3115(77) 90133-7.

URL http://www.sciencedirect.com/science/article/pii/0022311577901337

[51] W. Schenk, H. Nabielek, High-Temperature Reactor Fuel Fission Product Release and Distribution at 1600 to $1800^{\circ} \mathrm{C}$, Nuclear Technology 96 (3) (1991) 323-336.

URL http://epubs.ans.org/?a=34593

[52] K. FUKUDA, K. IWAMOTO, Diffusion and Evaporation of Fission Products in Coated Fuel Particles, Journal of Nuclear Science and Technology.

URL http://www.tandfonline.com/doi/abs/10.1080/18811248.1975.9733088\#.VX2_r_lVhBc

[53] J. C. Fisher, Calculation of Diffusion Penetration Curves for Surface and Grain Boundary Diffusion, Journal of Applied Physics 22 (1) (1951) 74. doi:10.1063/1.1699825.

URL http://scitation.aip.org/content/aip/journal/jap/22/1/10.1063/1.1699825

[54] H. SUZUKI, T. ISEKI, T. NAKAMURA, Reactions between $\mathrm{SiC}$ and $\mathrm{SrO}$ at High Temperatures, Journal of Nuclear Science and Technology.

URL http://www.tandfonline.com/doi/abs/10.1080/18811248.1973.9735434\#.vX2_0v1VhBc

[55] Y. Mishin, C. Herzig, Grain boundary diffusion: recent progress and future research, Materials Science and Engineering: A 260 (1-2) (1999) 55-71. doi:10.1016/S0921-5093(98)00978-2.

URL http://www.sciencedirect.com/science/article/pii/S0921509398009782

[56] Y. Mishin, An Atomistic View of Grain Boundary Diffusion, in: Defect and Diffusion Forum, Vol. 
363, 2015, pp. 1-11.

URL http://www.scientific.net/DDF.363.1

[57] P. R. Cantwell, M. Tang, S. J. Dillon, J. Luo, G. S. Rohrer, M. P. Harmer, Grain boundary complexions, Acta Materialia 62 (2014) 1-48. doi:10.1016/j.actamat.2013.07.037. URL http://ww.sciencedirect.com/science/article/pii/S1359645413005570 